\title{
Coupling between Northward-Propagating, Intraseasonal Oscillations and Sea Surface Temperature in the Indian Ocean*
}

\author{
Xiouhua Fu, Bin Wang, Tim Li, and Julian P. McCreary \\ International Pacific Research Center, School of Ocean and Earth Science and Technology, University of Hawaii at Manoa, \\ Honolulu, Hawaii
}

(Manuscript received 4 October 2002, in final form 24 February 2003)

\begin{abstract}
Using a hybrid atmosphere-ocean coupled model, it is shown that during the boreal summer northwardpropagating, intraseasonal oscillations (NPISOs) are strongly coupled to the underlying sea surface temperature (SST) in the Indian Ocean sector. On the one hand, the intraseasonal atmospheric convection changes the SST through solar radiation, latent heat flux, and mixed-layer entrainment; on the other, the induced SST fluctuations feed back to affect the intraseasonal convection. The preferential northward, rather than southward, propagation of boreal summer ISOs in the Indian Ocean is partially explained by an interaction among the summer-mean climate state, the atmospheric disturbances, and the ocean surface temperature.

A solution to an atmosphere-only model forced with daily SST produces much stronger NPISOs than a similar solution forced with monthly mean SST (AMIP-type run). The atmosphere-only model, however, even when it is forced by daily SST from the coupled model (with a small amount of noise in the initial and/or boundary conditions), is unable to reproduce the NPISOs in the coupled case. In the coupled system, intraseasonal SST anomalies are forced by intraseasonal atmospheric convection, and hence are in quadrature with the convection. In the stand-alone atmospheric model, however, SST acts only as a boundary forcing, and the resultant atmospheric convection has almost the same phase with the underlying SST. One consequence is that the intensity of the SST-forced intraseasonal convection in the stand-alone atmospheric model is considerably weaker than in the coupled model.

Finally, solutions indicate that the northward movement of the off-equatorial convection in the northern Indian Ocean is more closely related to local intraseasonal SST anomalies than to the equatorial eastward-moving Madden-Julian oscillation: Positive (negative) SST anomalies in the northern Indian Ocean lead the active (break) phases of the intraseasonal convection by about 2 pentads (10 days). Therefore, intraseasonal SST anomalies in the northern Indian Ocean are potentially a useful index to forecast active (break) spells of the south Asian summer monsoon.
\end{abstract}

\section{Introduction}

Using satellite cloud data, Yasunari $(1979,1980)$ found that the active (break) cycle of the south Asian summer monsoon is typically associated with northward-propagating intraseasonal oscillations (NPISOs) with a period of about 40 days. Krishnamurti and Subrahmanyan (1982) also documented the northward propagation of a train of troughs and ridges from the equator to the south Asian continent using the 1979 First Global Atmospheric Research Program (GARP) Global Experiment Program (FGGE) observations. The convec-

\footnotetext{
* School of Ocean and Earth Science and Technology Contribution Number 6138 and International Pacific Research Center Contribution Number 198.
}

Corresponding author address: Dr. Xiouhua Fu, IPRC, SOEST, University of Hawaii at Manoa, 1680 East West Road, POST Bldg. 401, Honolulu, HI 96822.

E-mail: xfu@soest.hawaii.edu tion region associated with NPISOs extends $60^{\circ}$ zonally $\left(60^{\circ}-120^{\circ} \mathrm{E}\right)$ and about $20^{\circ}$ meridionally, with propagation from the equatorial zone to about $30^{\circ} \mathrm{N}$ (Lau and Chan 1986; Wang and Rui 1990; Gadgil and Asha 1992), and the average speed of the northward propagation is about $1 \mathrm{~m} \mathrm{~s}^{-1}$ (Murakami 1976; Gadgil and Srinivasan 1990). The NPISOs occur in conjunction with equatorial disturbances. The disturbances can be initiated by cold-air outbreaks caused by large-scale fluctuations of westerly wave movements in the Southern Hemisphere (Yasunari 1981), or they may be associated with 40-50-day Madden-Julian oscillations (MJOs) that propagate eastward from the Indian Ocean into the western Pacific (Madden and Julian 1971).

The cause of the northward propagation is still not clear. Several studies have suggested that NPISOs are linked to MJOs. Krishnamurti et al. (1985), using the NWP analysis of the 1979 FGGE data, found that the planetary-scale MJO couples with a northward-propagating divergence wave, thereby modulating the Indian monsoon active (break) spells. Chen et al. (1988) sug- 
gested that the MJO couples with and steers northward low-level, 30-50-day monsoon troughs and ridges that originate near the equator through a transient local Hadley circulation (Yasunari 1981); this steering in turn induces active (break) cycles of the Indian summer monsoon. Lau and Chan (1986) argued that the northward propagation results from the interaction between MJOs and the monsoon circulations. Wang and Xie (1997) found that the northward-propagating convection in their model simulations was associated with an equatorial Kelvin-Rossby wave packet, which had a horseshoe-shaped convection "front" formed by the equatorial Rossby waves emanating from it. The convection front tilted northwestward from the equator to $20^{\circ} \mathrm{N}$, resulting in northward phase propagation as the entire wave packet migrated eastward. Lawrence and Webster (2002) used this theory to explain NPISOs in their observational study, emphasizing that the northward movement is an internal component of eastward-moving convection. Using NCEP reanalysis data, KemballCook and Wang (2001) found that NPISOs in the Indian Ocean during May and June are mainly associated with Rossby waves emanating from convection in the equatorial Indian Ocean. Similar conclusions were obtained by Annamalai and Slingo (2001) using European Centre for Medium-Range Weather Forecasts (ECMWF) reanalysis data.

Other analyses, however, suggest that NPISOs are a mode independent from MJOs. Wang and Rui (1990) traced all 122 tropical intraseasonal systems that appeared during 1975-85 over the Asia-Pacific area using pentad-mean intraseasonal outgoing longwave radiation (OLR) data. Of these events, 64\% were dominantly eastward, $22 \%$ were northward, and $14 \%$ were westward. In boreal summer, almost half of the northward propagation was not associated with MJOs. In contrast, the recent observational study of Lawrence and Webster (2002) using filtered (25-80 days) OLR data concluded that most of the northward-moving convection (78\%) is concurrent with the equatorial eastward movement, though independent NPISOs are also found. The discrepancy between these two studies is attributed to different criteria being used to define the independent northward mode (Lawrence and Webster 2002).

Webster (1983) attributed the cause of the northward propagation to feedback between the convection and land surface heat fluxes ahead of the ascending zone. Nanjundiah et al. (1992) suggested that larger precipitation efficiency (a function of convective instability and surface moisture) north of the convection zone is the primary cause. Another promising hypothesis is that airsea coupling plays an important role in NPISO dynamics. Recent observations obtained during JASMINE (Joint Air-Sea Monsoon Interaction Experiment; Webster et al. 2002) and BOBMEX (The Bay of Bengal Monsoon Experiment; Bhat et al. 2001) have provided high-quality observational data during boreal summer in the eastern Indian Ocean. The in situ observations showed significant SST fluctuations associated with NPISOs. Sengupta and Ravichandran (2001) and Sengupta et al. (2001), using in situ observations over the Bay of Bengal, concluded that intraseasonal SST variability during the 1998 summer season is largely forced by the intraseasonal variability of surface heat flux. Vecchi and Harrison (2002), using 3-yr (1998-2000) Tropical Rainfall Measuring Mission (TRMM) Microwave Imager (TMI) and OLR data, have documented coherent structures between the intraseasonal convection and surface winds with the underlying SST, particularly in the central-eastern Indian Ocean. They also found that the subseasonal SST variability in the Bay of Bengal is a good predictor of Indian monsoon breaks.

Kemball-Cook and Wang (2001), using observed OLR and National Centers for Environmental Prediction (NCEP) reanalysis data, documented the coherent northward propagations of intraseasonal OLR, vertical velocity $(500 \mathrm{hPa})$, zonal wind $(850 \mathrm{hPa})$, evaporation, surface temperature, shortwave radiation, moist static energy $(1000 \mathrm{hPa}), 10-\mathrm{m}$ convergence, and humidity $(1000 \mathrm{hPa})$. They suggested that air-sea coupling plays an important role in promoting NPISOs. The suggested physical processes are that a positive shortwave-radiation anomaly develops north of the equatorial convection. It warms up the sea surface there, increasing the low-level convergence and moist static energy, destabilizing the atmosphere, and leading the equatorial convection to propagate northward.

These observational and diagnostic studies suggest that the air-sea coupling is involved in NPISOs. It is not clear from the observations, however, whether the intraseasonal SST fluctuations are just a passive response to NPISOs or actively feed back to them (Bhat et al. 2001). The available concurrent air-sea observations associated with NPISOs in the Indian Ocean are too few to draw a complete picture of the interaction between NPISOs and the underlying ocean (Bhat et al. 2001; Vecchi and Harrison 2002). Further, it is intrinsically difficult to demonstrate cause-effect relationships from observational studies alone.

Given these limitations, coupled models therefore provide a useful alternative to explore the influences of air-sea coupling on NPISOs. For example, KemballCook et al. (2002) used a hybrid-coupled model to assess the impacts of air-sea coupling on the intraseasonal variability. They noticed that the coupled model is able to simulate boreal winter ISOs with a more coherent spatial structure and a more realistic phase speed than the stand-alone atmospheric model. Further, during the May-June season the coupled run shows more consistent northward propagation in the Indian Ocean than the uncoupled runs. Limitations of their study are that all composites were based on the eastward-moving equatorial convections and the number of NPISO events used in the composites was small and limited in the MayJune season.

In this study, we extend the study of Kemball-Cook 
et al. (2002), using an improved version of the previous coupled model, particularly in terms of its cold bias in the western Pacific (Fu et al. 2002). We focus on all the NPISO events during boreal summer from May to September. Atmospheric and oceanic processes associated with NPISOs are investigated using case studies and statistical analyses. Questions that we address include: Does air-sea interaction significantly impact NPISOs? If yes, what are the major physical processes involved, particularly at the air-sea interface? Further, if the intraseasonal SST anomaly is important for NPISOs, can we reproduce the NPISOs with an atmosphere-only model forced by daily SST? We also explore why northward propagation, rather than the southward propagation, is favored in the south Asian summer monsoon. Finally, the relationship between NPISOs and eastwardmoving MJOs will be reexamined.

In section 2, the coupled model and its atmospheric and oceanic components are introduced; in addition, three sensitivity experiments using an atmosphere-only model are defined. In section 3, the coupled model simulating the mean climate in the Asia-western Pacific region and NPISOs in the Indian sector is briefly validated and the intensification of NPISOs by air-sea coupling is presented. In section 4, we discuss the major atmospheric and oceanic processes associated with NPISOs in the coupled model. The relationship between NPISOs and MJOs is examined in section 5. Finally, summary and discussion are given in section 6 .

\section{The coupled model and experimental design}

\section{a. Atmospheric component}

The atmospheric component of the coupled model is the ECHAM4 AGCM, which is documented in detail by Roeckner et al. (1996). We used the T30 version (with a horizontal resolution of about $3.75^{\circ}$ ) instead of the standard T42 version, because it produces similar results as the higher-resolution version but requires fewer computational resources (Stendel and Roeckner 1998). The model has 19 vertical levels extending from the surface to $10 \mathrm{hPa}$. Its land surface scheme is a modified bucket model with improved parameterization of rainfall runoff (Dumenil and Todini 1992). The surface fluxes of momentum, heat, water vapor, and cloud water are based on the Monin-Obukhov similarity theory. The vertical diffusion in the model is computed with a highorder closure scheme that depends on the turbulent kinetic energy. Gravity wave drag associated with orographic gravity waves is simulated after Miller et al. (1989). The mass flux scheme of Tiedtke (1989) for deep, shallow, and midlevel convection has been used with modified closure schemes for penetrative convection and the formation of organized entrainment and detrainment (Nordeng 1995). The radiation scheme is a modified version of the European Center for MediumRange Weather Forecasts scheme. Two- and six-band intervals are used in the solar and terrestrial part of the spectrum, respectively.

\section{b. Ocean component}

The ocean component of the coupled model is a tropical upper-ocean model with intermediate complexity, which was originally developed by Wang et al. (1995) and improved by Fu and Wang (2001) in the tropical Pacific. It is a $2 \frac{1}{2}-$-layer system, consisting of a surface mixed layer (layer 1) and a thermocline layer in which temperature is assumed to decrease linearly (layer 2), overlying a deep motionless ocean with a constant reference temperature. The layer- 2 water that is entrained into layer 1 is parameterized in terms of the layer-2 vertical temperature gradient. The mixed-layer turbulence parameterization follows that of Gaspar (1988), which treats penetrating solar radiation realistically. The ocean model is able to reproduce the annual cycles of SST, upper-ocean currents, and mixed-layer thickness in the tropical Pacific quite well (Fu and Wang 2001; Wang and Fu 2001).

In this study, the ocean model has been extended to cover both the tropical Indian Ocean and Pacific Ocean (from $30^{\circ} \mathrm{S}$ to $30^{\circ} \mathrm{N}$ ) with realistic but simplified coastal boundaries. The spatial resolution of the model is $2^{\circ}$ longitude by $1^{\circ}$ latitude, and the time step is $3 \mathrm{~h}$. Noflux conditions for temperature and no-slip conditions for velocities are applied at the coastal boundaries.

\section{c. Coupling}

The atmosphere and ocean models are only coupled in the tropical Indian and Pacific Oceans. Outside these regions, the underlying SST is specified to be the climatological monthly mean SST averaged for the 16-yr dataset (1979-94) used as the boundary conditions of the Atmospheric Model Intercomparison Project II (AMIP II) experiments (Taylor et al. 2000). To maintain the continuity of the boundary forcing, SST at the northern and southern boundaries of the ocean model is relaxed to the observations (Fu and Wang 2001). The system is externally forced by seasonally varying solar radiation forcing. To avoid the exaggerated westward extension of Pacific cold tongue in the previous version coupled model (Kemball-Cook et al. 2002), the model SST in the central-eastern Pacific (east of date line) is relaxed toward the observations ( $\mathrm{Fu}$ et al. 2002) with an $e$-folding timescale of half a day. The atmospheric component exchanges information with the ocean component once per day, thereby providing daily mean surface winds and heat fluxes to force the ocean model. In return, the ocean component sends daily mean SST back to the model atmosphere.

The initial atmospheric state is taken from the ECMWF analysis at 1 January 1988. The initial oceanic state is the January state of a 10-yr integration of the ocean model forced by observed climatological surface 
TABLE 1. Design of the atmosphere-only sensitivity experiments.

\begin{tabular}{lccc}
\hline \hline Label & SST forcing & $\begin{array}{c}\text { Length of } \\
\text { integration } \\
\text { (yr) }\end{array}$ & No. of runs \\
\hline Mean & $\begin{array}{c}\text { Climatological monthly mean } \\
\text { SST from the coupled run }\end{array}$ & 16 & 1 \\
Daily & $\begin{array}{c}\text { Last 10-yr daily mean SST from } \\
\text { the coupled run }\end{array}$ & 10 & 1 \\
Daily9 & $\begin{array}{c}\text { One-yr (year 9) daily mean SST } \\
\text { from the coupled run }\end{array}$ & 1 & 10 \\
\hline
\end{tabular}

winds and heat fluxes. The coupled model is integrated for $16 \mathrm{yr}$, and the last $10 \mathrm{yr}$ of the run are used in the statistical analyses reported later. We refer to this simulation as the coupled run.

\section{d. Atmosphere-only experiments}

To investigate the roles of air-sea coupling and intraseasonal SST anomalies on NPISOs, three sensitivity experiments are conducted with the stand-alone atmospheric model, which we label mean, daily, and daily9 (Table 1). In the mean experiment, the climatological monthly mean SST from the coupled run is used to force the model, and the initial conditions are the same as those for the coupled integration; it is integrated $16 \mathrm{yr}$ and the output from the last $10 \mathrm{yr}$ is used in the statistical analyses. For the daily experiment, the SST forcing is daily mean SST from the last $10 \mathrm{yr}$ of the coupled run, and the initial conditions are unchanged. In the daily9 experiment, the solutions of 10 ensemble runs are obtained; the runs all use daily mean SST from year 9 of the coupled run as boundary forcing, but with initial conditions taken from 10 different days (1-10 January) of a long-term atmospheric integration.

Results from the first two experiments are compared to those from the coupled run to assess the impacts of air-sea coupling and intraseasonal SST anomalies on NPISOs. The last experiment is conducted to demonstrate the response of the atmosphere to the intraseasonal SST forcing.

\section{Solutions}

\section{a. Validation of the coupled solution}

In this section, we demonstrate that basic properties of the south Asian summer monsoon and NPISOs in the Indian sector are simulated by the coupled model. Figure 1 shows annual-mean SST from the observations, the coupled solution, and their difference. The warm pool in the Indian Ocean and western Pacific Ocean is reproduced, although the area with SST higher than $28^{\circ} \mathrm{C}$ is smaller in the solution. Indeed, the model SST is systematically lower than in the observations $\left(\sim-0.5^{\circ} \mathrm{C}\right)$ over most of the region, a consequence of the downward net surface heat flux in the atmospheric model being somewhat too small (Fu et al. 2002).
Figure 2 plots rainfall and $850-\mathrm{hPa}$ winds from the observations and the coupled solution in boreal summer (June-July-August). The solution captures the observed rainfall maxima over the Bay of Bengal, equatorial Indian Ocean, western North Pacific, and the South Pacific convergence zone (SPCZ). The rainfall center in the eastern Arabian Sea, however, is not reproduced, which is probably due to coarse horizontal resolution used in this study (Stendel and Roeckner 1998). The rainfall in the South China Sea tends to shift eastward and lock onto the Philippine island chain, as in the stand-alone ECHAM4 simulation (Roeckner et al. 1996).

The northward propagation of active (break) events in the Indian sector is also simulated. Two-dimensional $(y, t)$ time series are useful for illustrating NPISOs (Yasunari 1979, 1981; Webster 1983) because the primary propagation direction of atmospheric disturbances is northward in this region with a large zonal scale (about $60^{\circ}$ of longitude). Figure 3 shows latitude-time plots of rainfall rates from observations averaged between $65^{\circ}$ and $95^{\circ} \mathrm{E}$ for an individual year with strong NPISOs [year 1979 of Climate Prediction Center (CPC) Merged Analysis of Precipitation (CMAP) data] and the coupled solution (year 11). Likewise, the coupled solution shown here is for a year with strong model NPISOs. From May to September, four primary northward-propagating events are discernible in both the observations and the coupled solution, with the two strongest events appearing in peak summer (June-July-August). Although the near-equatorial intraseasonal variations in the coupled solution appears to be too strong in comparison to the observations, both the active (break) regimes of the south Asian summer monsoon and the prevalent northward propagation are well reproduced.

\section{b. Comparison with atmosphere only}

There are several limitations in the study of NPISOs using composite analyses. First, it is necessary to set subjective criteria for picking the cases to include in the composites. Second, typically, a different number of cases must be selected for different simulations. Third, since the speed of NPISOs is not constant, but varies on a broad range (the corresponding periods could be from 20 to 70 days), the composite may not necessarily reflect the real differences between two potential simulations. Because of these problems, we utilize case studies and statistical analyses to analyze our model output.

A wavenumber-frequency analysis is used to quantify the total variance associated with the northward (southward)-propagating disturbances in different periods and wavelengths (Hayashi 1982; Teng and Wang (2002, manuscript submitted to J. Climate, hereafter TW02). The basic idea of this technique is to transform time series from a spatial-time domain to a wavenumberfrequency domain. Thus, variability associated with different frequencies, spatial scales, and propagation di- 
(a)



(b)

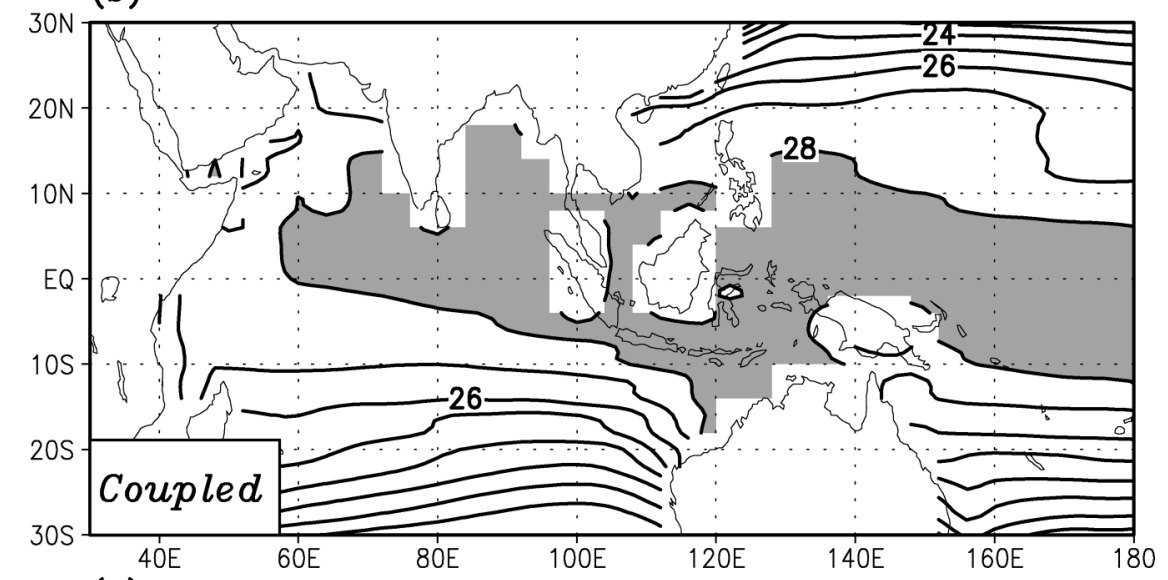

(c)

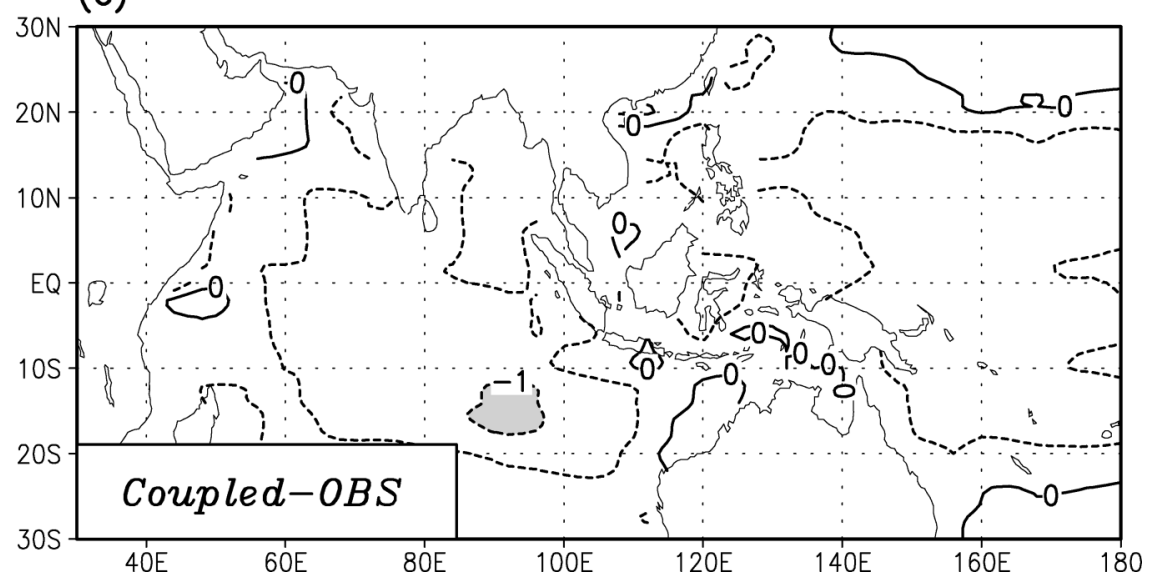

FIG. 1. Annual mean SST $\left({ }^{\circ} \mathrm{C}\right)$ from (a) observations, (b) the coupled solution, and (c) their difference. The contour interval is $1^{\circ} \mathrm{C}$ in (a) and (b) but is $0.5^{\circ} \mathrm{C}$ in (c).

rections are separated. Using this method, for example, Wheeler and Kiladis (1999) successfully identified the tropical waves that were summarized by the dispersion relationship in Matsuno (1966).

To focus on the NPISOs in the Indian sector, we conduct wavenumber-frequency analysis for daily mean rainfall averaged in a zonal band extending from $65^{\circ}$ to $95^{\circ} \mathrm{E}$, for latitudes between $10^{\circ} \mathrm{S}$ and $30^{\circ} \mathrm{N}$ and for 10 boreal summers (from May to September). Figure 4 shows the resulting 10-yr mean spectral density in the coupled run as well as its differences from those for the daily and the mean runs. In the coupled solution (Fig. 
(a)

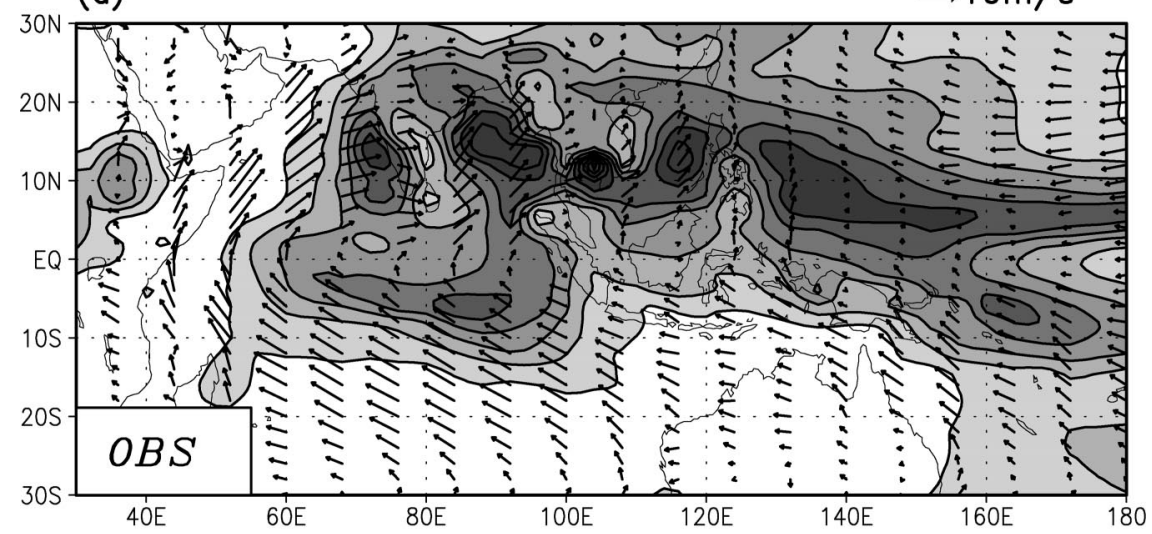

(b)

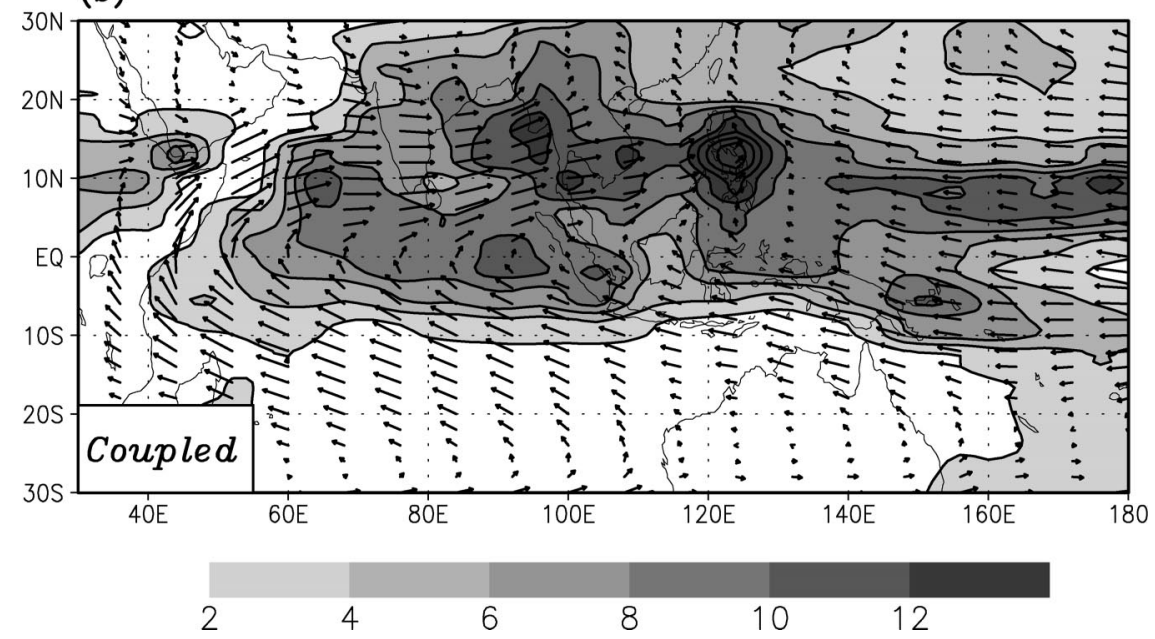

FIG. 2. Rainfall rates $\left(\mathrm{mm} \mathrm{day}^{-1}\right)$ and $850-\mathrm{hPa}$ winds averaged during Jun-Jul-Aug for (a) observations (CMAP rainfall and winds from ECMWF analysis) and (b) the coupled solution.

4a), the northward-propagating intraseasonal variability is considerably larger than that of the southward-propagating disturbances. At the spectrum maximum, the period is 50 days and the wavelength is about $40^{\circ}$. The corresponding northward-propagating speed is about 1 $\mathrm{m} \mathrm{s}^{-1}$. The difference between the coupled and the daily runs (Fig. 4b) indicates that the latter solution has weaker NPISOs: Air-sea coupling increases the intensity of NPISOs by about $30 \%$, particularly for periods around 30 days. The difference between the coupled run and the mean run (Fig. 4c) shows that the NPISOs in the mean run are much weaker than in the coupled run at all periods from 20 to 90 days. For periods near 50 days, the intensity of the NPISOs in the mean run is only about half of that in the coupled run.

These results clearly show that air-sea coupling acts to intensify NPISOs in the Indian sector. The large difference between Fig. 4b and Fig. 4c may explain why NPISOs are systematically weak in the AMIP-type runs, which force the atmosphere with monthly mean, rather than daily mean, sea surface temperature.

\section{Processes}

In this section, the atmospheric and oceanic processes associated with two NPISO events in a particular boreal summer from the coupled run are analyzed. Statistical analyses with the complete $10-\mathrm{yr}$ dataset are then used to generalize the findings from the case study.

For these analyses, all fluctuations in solutions with periods from 20 to 70 days are defined to be intraseasonal oscillations. The intraseasonal signals are extracted from the solution's daily output following the method of Rui and Wang (1990). First, the annual cycle is defined to be the sum of the annual mean and the first three harmonics from the daily data. It is then subtracted from the original daily data to yield a daily anomaly. Superseasonal variations are then estimated by a 3month weighted-mean anomaly of this time series. After removing the superseasonal variations from the daily anomaly time series, we compute 5-day mean anomalies, which describe variations with timescales roughly from 10 days to 3 months. Finally, only harmonics from 

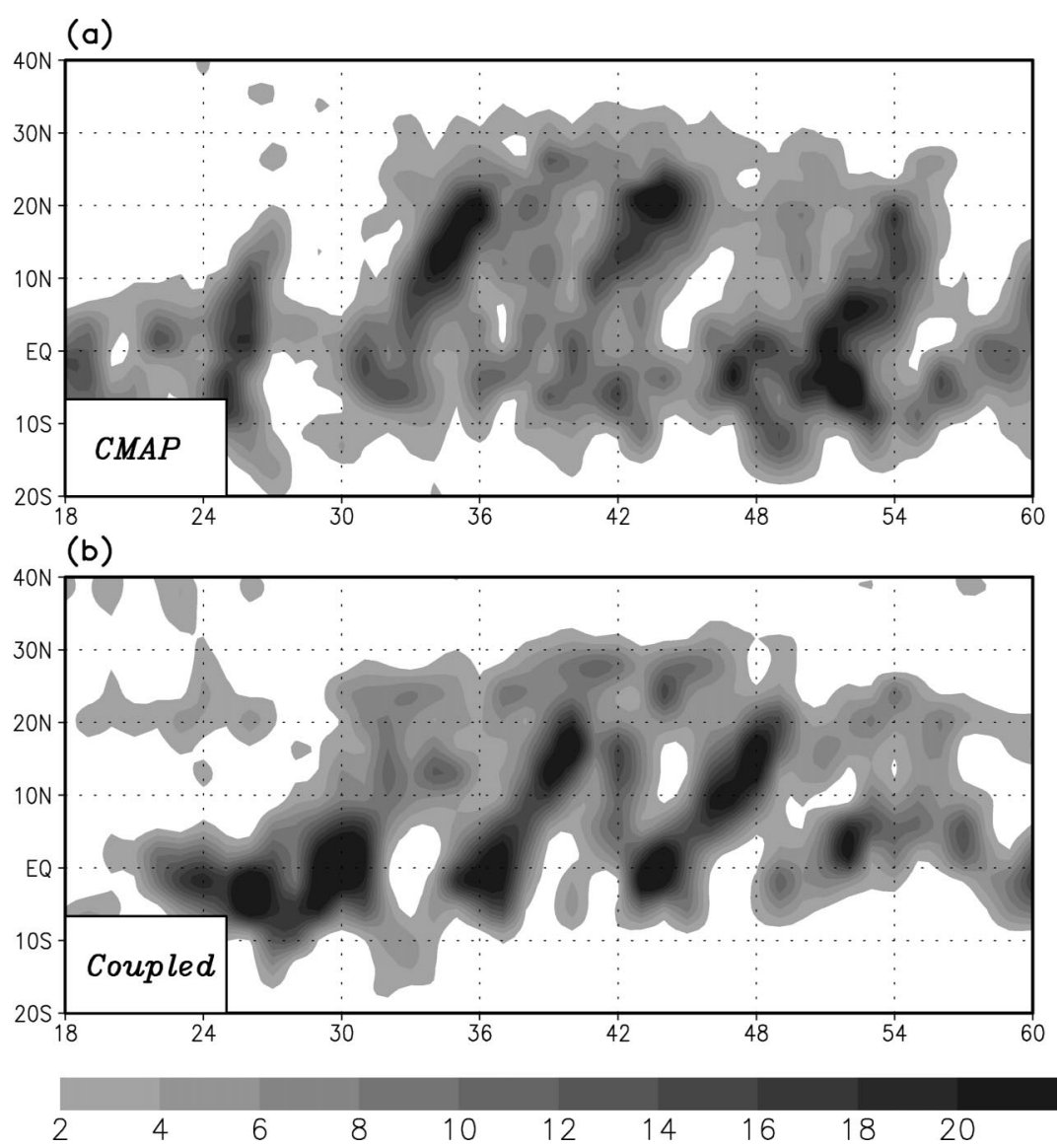

FIG. 3. Latitude-time plots of total rainfall rate $\left(\mathrm{mm}^{-1 a y}{ }^{-1}\right)$ averaged between $65^{\circ}$ and $95^{\circ} \mathrm{E}$ from (a) observations (CMAP, year 1979), (b) the coupled solution (year 11) from early Apr (pentad 18) to late Oct (pentad 60).

5 to 17 (with periods from about 20 to 70 days) are extracted from the 5-day mean anomaly. The sum of harmonics from 5 to 17 forms the 10 -yr dataset used in the following analyses.

\section{a. Coupling between NPISOs and SST}

Figure 5 shows latitude-time plots of rainfall and SST in the coupled run averaged between $65^{\circ}$ and $95^{\circ} \mathrm{E}$ for year 9. From early June (pentad 30) to middle August (pentad 45), two northward-propagating wet (dry) cycles are observed. The time interval between the two events is about 30 days. The first wet episode propagates from the equatorial Indian Ocean to about $17^{\circ} \mathrm{N}$ taking about 4 pentads (from pentad 34 to 38), a speed of about $1 \mathrm{~m}$ $\mathrm{s}^{-1}$, very similar to the observations (Yasunari 1979). The next wet episode propagates slower than the first one, and rapidly decays in its northward progression.

For both wet (dry) cycles, the underlying SST fluctuations are in quadrature with the rainfall perturbations, with the maximum positive SST anomaly lagging (leading) the peak dry (wet) phase by $2-3$ pentads. This is consistent with the observed results of Vecchi and Har- rison (2002). The positive SST anomaly is generated during the dry phase of the NPISO. On the other hand, the SST anomaly may also contribute to the development of the coming NPISO wet phase. These relationships are explored further in the following sections.

\section{1) ATMOSPHERE-TO-OCEAN PROCESSES}

Analysis of the heat budget of the oceanic mixed layer indicates that the intraseasonal SST anomalies associated with NPISOs are primarily caused by the changes of surface heat flux and entrainment through the oceanic mixed layer. The governing equation for SST (mixedlayer temperature $T_{1}$ ) in the ocean model is

$$
\begin{aligned}
\frac{\partial T_{1}}{\partial t} & +\mathbf{v}_{1} \cdot \nabla T_{1} \\
& =-\frac{W_{e}}{h_{1}} H\left(W_{e}\right)\left(T_{1}-T_{e}\right)+\frac{Q_{0}-Q_{h 1}}{\rho_{r} c_{w} h_{1}}+v \nabla^{2} T_{1},
\end{aligned}
$$

where $\mathbf{v}_{1}$ and $h_{1}$ are current and thickness fields, $v$ is the coefficient of horizontal diffusion, $Q_{0}$ and $Q_{h 1}$ are downward heat fluxes at the surface and the mixed-layer 

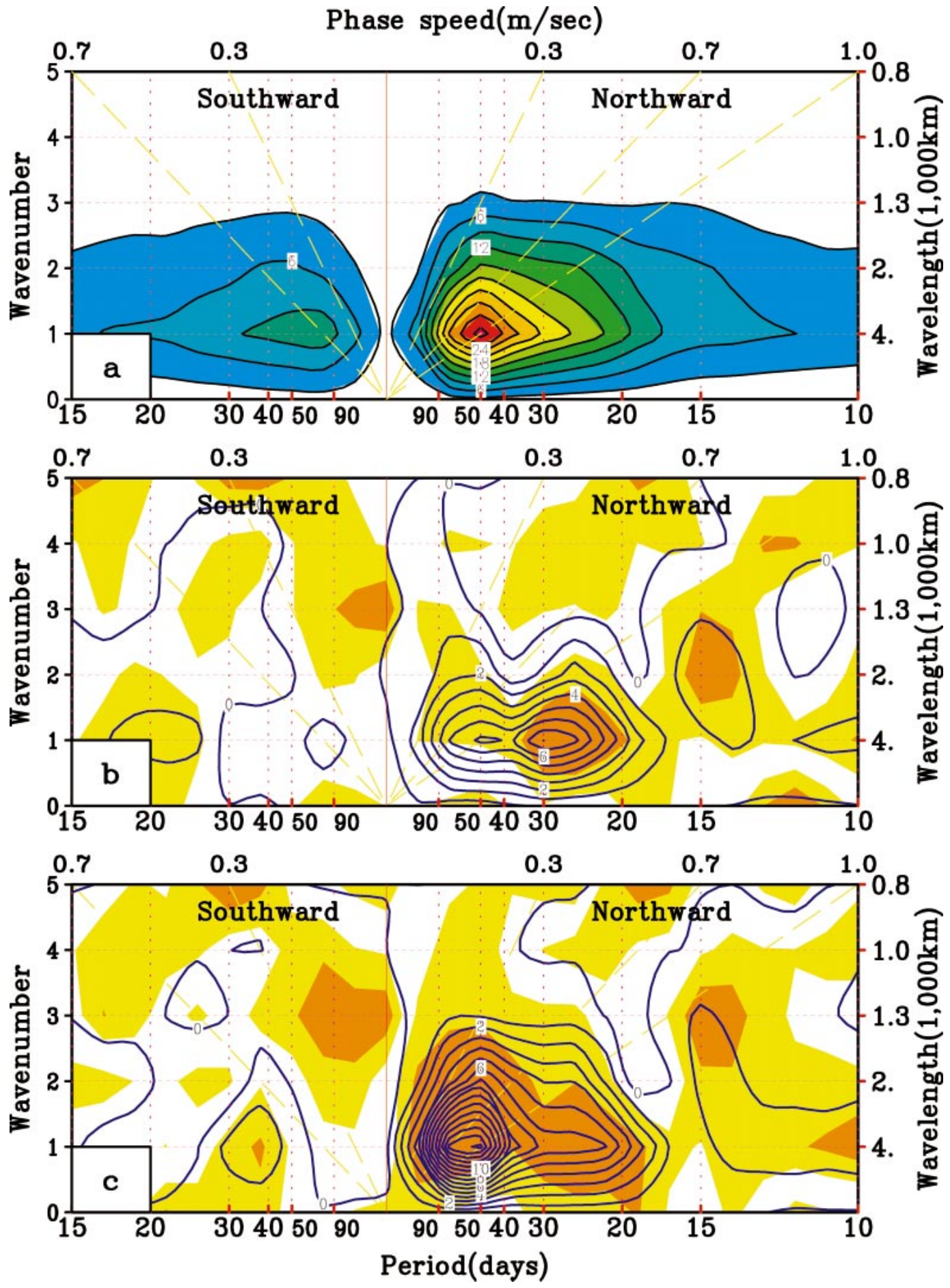

FIG. 4. Wavenumber-frequency spectrum (a) from the coupled run, (b) the difference between the coupled run and the daily run, and (c) the difference between the coupled run and the mean run (Table 1). The contour interval is 3 $\left(\mathrm{mm} \text { day }^{-1}\right)^{2}$ in (a) but $1\left(\mathrm{~mm} \mathrm{day}^{-1}\right)^{2}$ in (b) and (c). Yellow (orange) shaded areas in (b) and (c) represent the significance larger than $75 \%(95 \%)$. 

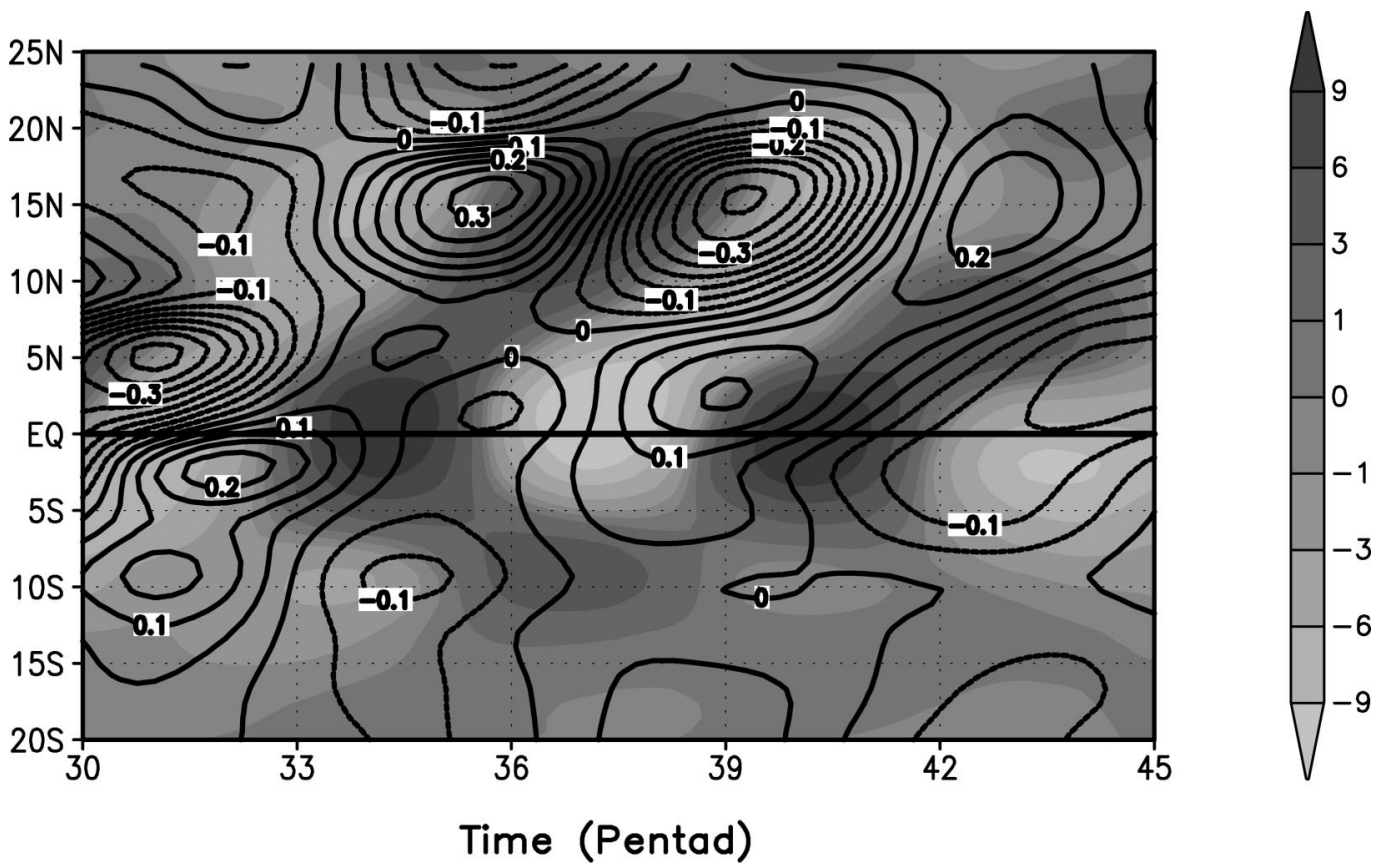

FIG. 5. Latitude-time plots of intraseasonal rainfall rate $\left(\mathrm{mm}\right.$ day ${ }^{-1}$; shaded $)$ and $\mathrm{SST}\left({ }^{\circ} \mathrm{C}\right.$; contours $)$ averaged between $65^{\circ}$ and $95^{\circ} \mathrm{E}$, from early Jun (pentad 30) to mid-Aug (pentad 45). The contour interval is $0.05^{\circ} \mathrm{C}$.

base (the latter representing penetrating solar radiation), $W_{e}$ is the rate at which layer-2 water entrains into layer 1 , and $H\left(W_{e}\right)$ is a Heaviside step function. The temperature of the entrained water $\left(T_{e}\right)$ is determined from the mean vertical temperature gradient in the thermocline layer. A detailed explanation of the parameters and their values was given in Fu and Wang (2001).

Figure 6 shows the intraseasonal changes of surface heat flux, vertical entrainment, and zonal and meridional advections associated with the two wet (dry) cycles in Fig. 5. The horizontal diffusion term is very small and is excluded from the figure. The total rate of change of SST averaged between $65^{\circ}$ and $95^{\circ} \mathrm{E}$ is primarily determined by two terms: the net surface heat flux (Fig. 6a) and the entrainment flux (Fig. 6b). The surface heat flux term has larger amplitude and both terms propagate northward with almost the same phase. The zonal-advection term is very small. The meridional-advection term has a similar magnitude to the entrainment term, particularly near the equator; however, its variations are not systematically related to the surface heat flux, entrainment, or the total rate of change of SST (Fig. 6e).

The rate of change of SST is influenced by both heat fluxes and mixed-layer thickness (Wang and Fu 2001). The time evolution of total mixed-layer thickness is given in Fig. 6f. The mixed-layer thickness is shallower in early summer than in late summer, except in the northern tip of the Indian Ocean. It is also shallower in the northern Indian Ocean than in the southern Indian Ocean. This temporal variation and north-south asymmetry of mixed-layer thickness favor a large rate of change of SST occurring in early summer and in the northern In- dian Ocean (Fig. 5), even if the heat fluxes are uniform in time and space.

The net surface heat flux at intraseasonal timescales is highly correlated with the NPISOs (Fig. 7a), particularly in the Northern Hemisphere (downward surface heat flux is taken to be positive throughout this paper). Positive (negative) downward net surface heat flux corresponds to the dry (wet) phase. The major contributors for the net surface heat flux perturbations are the solar radiation and latent heat flux. The increase and decrease of solar radiation is directly associated with the reduced and increased cloud amounts in the wet and dry phases, respectively (Fig. 7b).

Both the surface zonal wind and latent heat flux show coherent northward propagation in the Northern Hemisphere (Fig. 7c). Easterly wind anomalies correspond to reduced latent heat flux in the Northern Hemisphere, but increased latent heat flux in the Southern Hemisphere. The latent heat flux anomalies can be explained by the surface zonal wind perturbations. This equatorial asymmetry of latent heat flux responding to the same zonal wind anomaly is determined by the asymmetry of summer-mean zonal winds in the Indian sector. In the coupled system, the reduced latent heat flux warms up the northern Indian Ocean, favoring equatorial convection to move northward. We will return to this point later.

\section{2) OCEAN-TO-ATMOSPHERE PROCESSES}

The diagnostic study of Kemball-Cook and Wang (2001) suggested that positive SST anomaly in the northern Indian Ocean leads the northward propagation of equa- 
(a) Surface Heat Flux Term

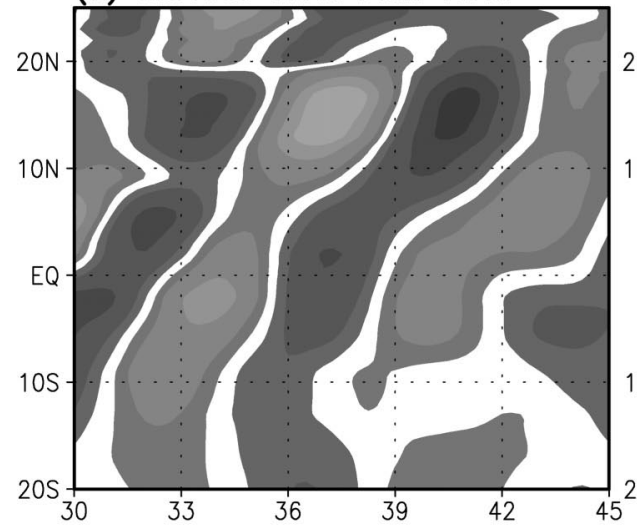

(c) Zonal Advection Term

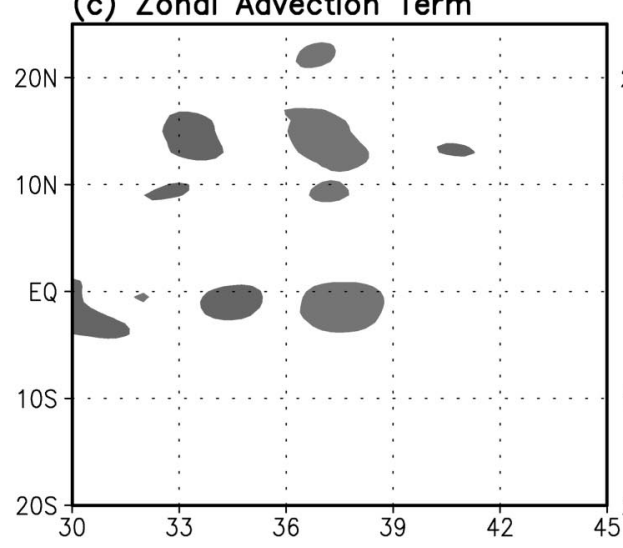

(e) Change Rate of SST ( $\mathrm{c} / \mathrm{mon}$ )

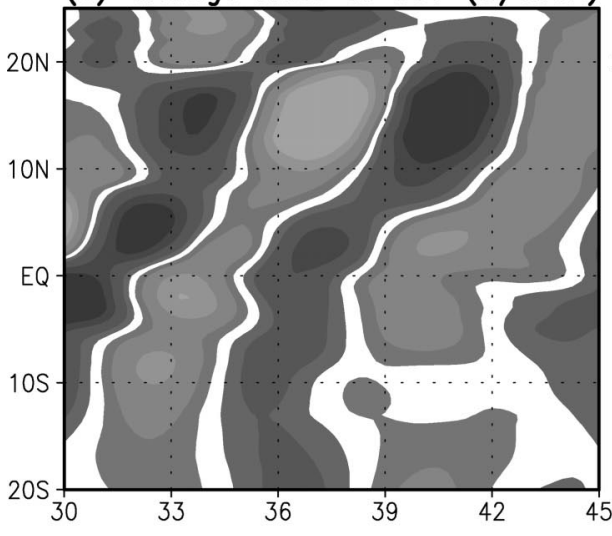

(b) Entrainment Term

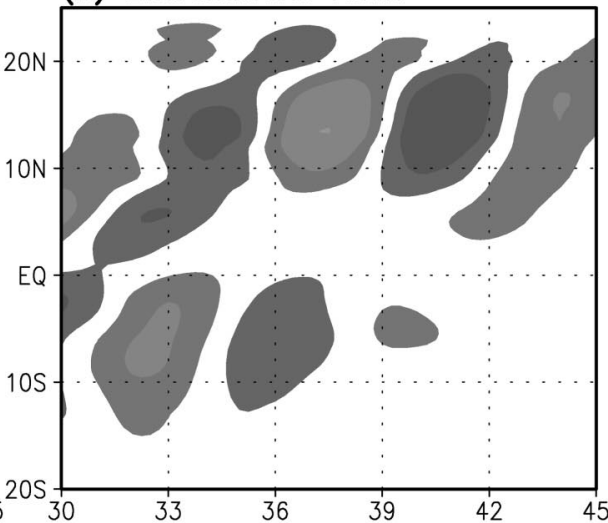

(d) Meridional Advection Term

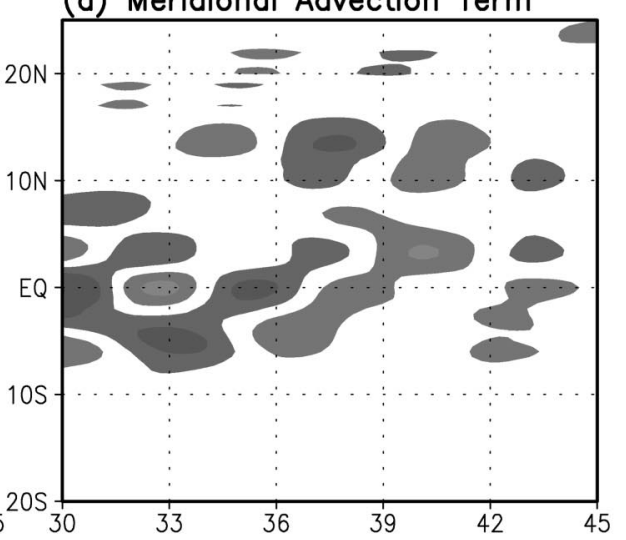

(f) Total Mixed-layer Depth (m)

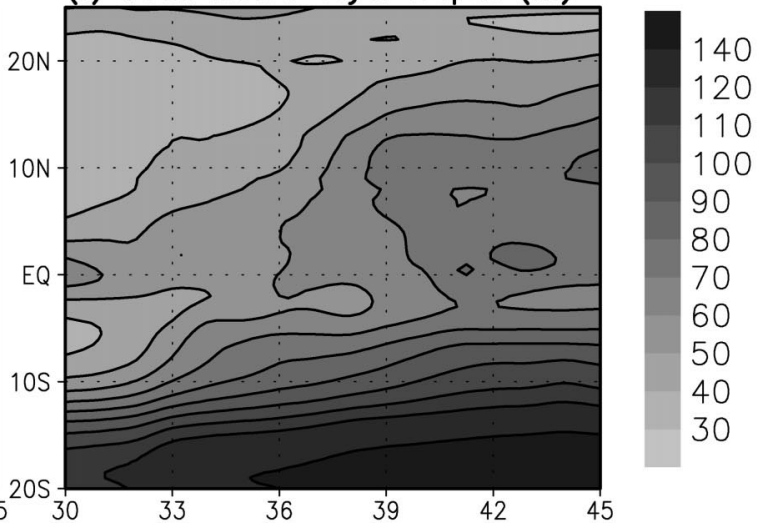

Time (Pentad)

FIG. 6. Latitude-time plots of intraseasonal oceanic mixed-layer heat budget terms $\left({ }^{\circ} \mathrm{C}\right.$ month $\left.{ }^{-1}\right)$, showing (a) surface heat flux term, (b) mixed-layer entrainment term, (c) zonal advection term, (d) meridional advection term, (e) the rate of total change of SST, and (f) total mixed-layer thickness (m) from early Jun (pentad 30) to mid-Aug (pentad 45).

torial convection by increasing low-level convergence and moist static energy (their Fig. 12). Later, Kemball-Cook et al. (2002) found that low-level convergence leads convection significantly south of $5^{\circ} \mathrm{N}$, but that these two variables have almost the same phase north of $5^{\circ} \mathrm{N}$.

To see whether their findings stand in this study, the surface divergence and convective instability associated with the two wet (dry) cycles in Fig. 5 are examined. In the northward progression of the intraseasonal convection, the surface convergence (divergence) and the active (suppressed) convection are nearly in phase (Fig. $8 \mathrm{a})$. Only near the equator does the convergence lead the convection by several days for the first cycle. Figure $8 \mathrm{~b}$ shows the relationship between the NPISO convec- 



FIG. 7. Latitude-time plots for intraseasonal variability averaged between $65^{\circ}$ and $95^{\circ} \mathrm{E}$, showing (a) rainfall rates ( $\mathrm{mm}$ day $^{-1}$; shading) and net surface heat flux ( $\mathrm{W} \mathrm{m}^{-2}$; contours), (b) rainfall rates $\left(\mathrm{mm} \mathrm{day}^{-1}\right.$; shading) and surface solar radiation ( $\mathrm{W} \mathrm{m}^{-2}$; contours), and (c) zonal wind ( $\mathrm{m} \mathrm{s}^{-1}$; shading) and surface latent heat flux ( $\mathrm{W} \mathrm{m}^{-2}$; contours), from early Jun (pentad 30) to mid-Aug (pentad 45). The contour interval for heat flux is $20 \mathrm{~W} \mathrm{~m}^{-2}$, with positive values indicating a downward flux into the ocean.

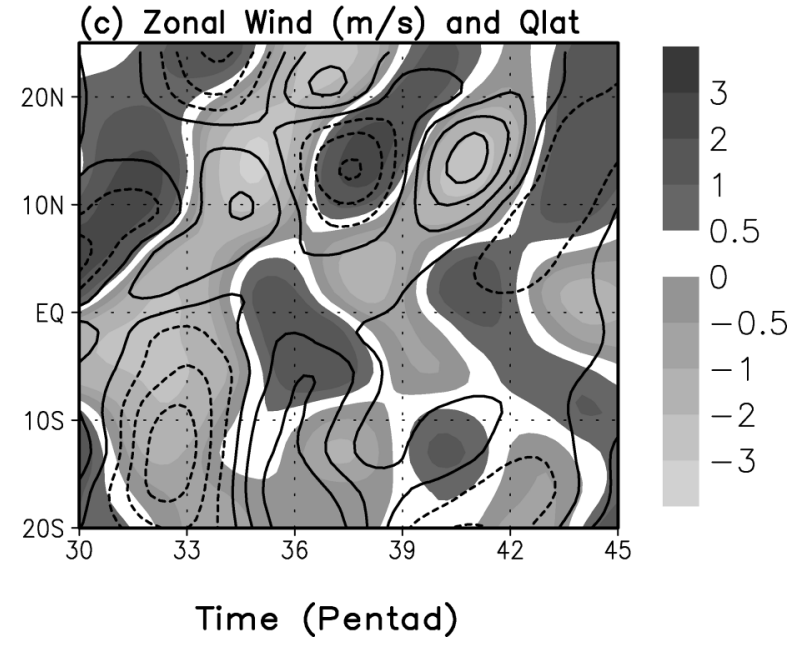

tion and convective instability, where convective instability is represented by the difference of moist static energy between 1000 and $500 \mathrm{hPa}$. The figure shows that suppressed (active) convection corresponds to positive (negative) convective instability. In this specific case, there is no obvious lead of low-level convergence and convective instability to the convection. The reason may be the strong coupling between convection with surface convergence and convective instability and/or the tilted rainbelt (see Fig. 14 below, which suggests that zonal averaging may mix phase information). The lag correlation between intraseasonal SST, surface divergence and rainfall at $5^{\circ} \mathrm{N}, 90^{\circ} \mathrm{E}$ for all 10 boreal summers (Fig. 9) does suggest that positive SST anomaly can enhance convection by first increasing the lowlevel convergence. In Fig. 9, positive SST anomaly appears about two pentads before approaching the maximum, surface convergence occurs about one pentad later, then positive rainfall starts.

In order to demonstrate directly that the atmosphere does respond to the model intraseasonal SST fluctuations, we conduct the daily9 experiment (section $2 \mathrm{~d}$, Table 1) that comprises 10 ensemble runs with the standalone atmospheric model. The ensemble means of in- traseasonal SST and convection are shown in Fig. 10. The prescribed northward-propagating SST is almost the same as that in the coupled run (Fig. 5); and its magnitude near $15^{\circ} \mathrm{N}$ is about $0.7^{\circ} \mathrm{C}$, which is similar to the observations from the BOBMEX experiment (Bhat et al. 2001). The significant rainfall response (Fig. 10) demonstrates that the intraseasonal SST systematically feeds back to the atmosphere. In the ECHAM4 model, the intraseasonal SST anomalies influence convection by changing the surface heat fluxes and convective instability. For example, a positive SST anomaly will increase the local surface sensible, latent heat fluxes and convective available potential energy (CAPE), which is an important parameter in the ECHAM4 model to control the cumulus convection (Nordeng 1995), thus leading to stronger convection.

\section{3) Phase RELATIONSHIP BETWEEN NPISOS AND SST}

Comparison of Figs. 5 and 10 reveals that the intraseasonal rainfall associated with NPISOs has a quite different phase relationship with underlying SST between the coupled run and the daily run: The rainfall 


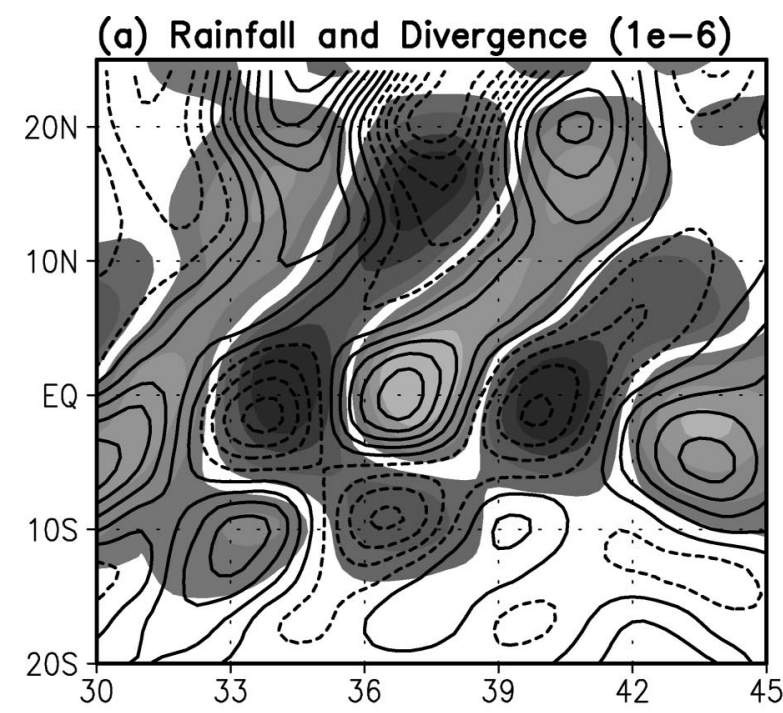

(b) Rainfall and dh (1000mb-500mb)
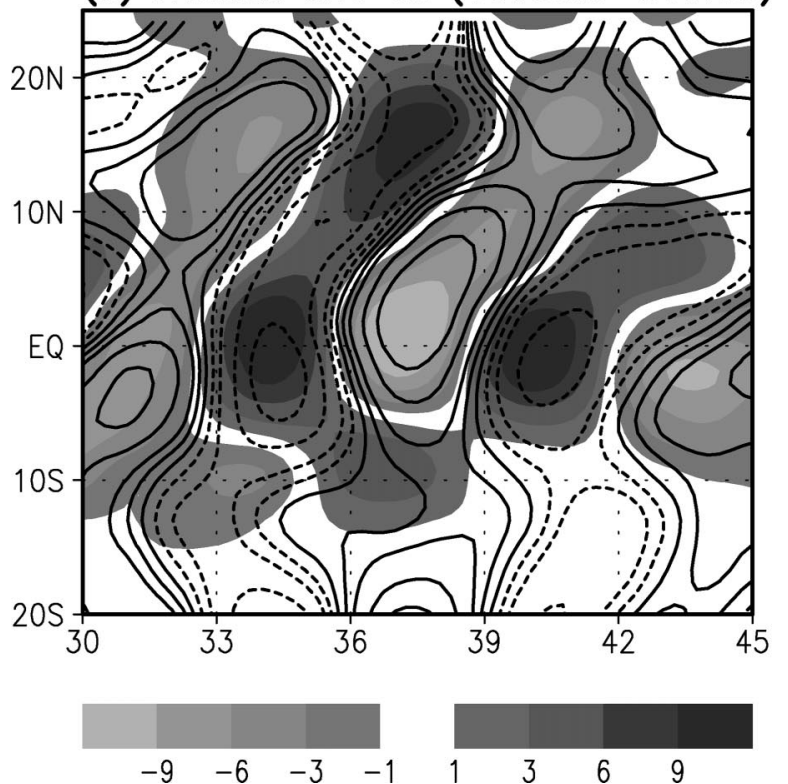

FIG. 8. Latitude-time Hovmoeller plots for intraseasonal variability averaged between $65^{\circ}$ and $95^{\circ} \mathrm{E}$, showing (a) rainfall rate $\left(\mathrm{mm} \mathrm{day}^{-1}\right.$; shading) and surface divergence (contours), (b) rainfall rate (mm day $^{-1}$; shading) and difference of moist static energy between 1000 and $500 \mathrm{hPa}$ (contours). The contour interval for surface divergence is $1 \mathrm{e}^{-6} \mathrm{~s}^{-1}$; the contour interval for the moist static energy is 1000 $\mathrm{J} \mathrm{kg}^{-1}$ with extra contour lines of -500 and $500 \mathrm{~J} \mathrm{~kg}^{-1}$.

is in quadrature with SST for the coupled run (Fig. 5), but almost in phase with SST for the atmosphere-only run (Fig. 10). This result is only from a specific year. Does this relationship stand for all the 10-yr data?

To answer this question, we calculate the lag correlation between intraseasonal rainfall and local SST over the Arabian Sea and the Bay of Bengal, using 10-yr boreal summer output from the coupled run and atmosphere-only run (daily in Table 1). Figure 11 presents 6-pentad lag correlations for the coupled model. It is

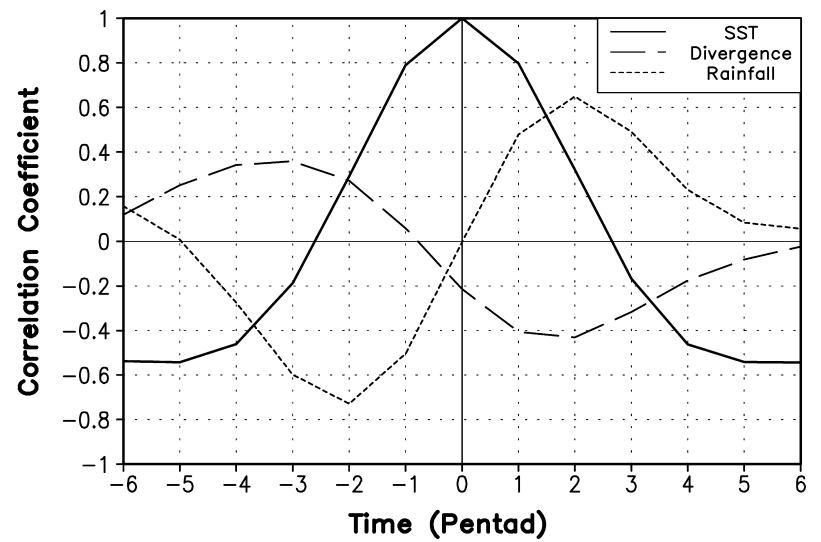

FIG. 9. The lag correlation of intraseasonal SST with surface divergence and rainfall at $5^{\circ} \mathrm{N}, 90^{\circ} \mathrm{E}$, for last 10 boreal summers in the coupled run.

clear that the local SST systematically leads intraseasonal rainfall by 2 pentads with a significant correlation coefficient of 0.6. Also the local SST shows a significant negative correlation with rainfall with a lag of 2 pentads, suggesting the modulation of intraseasonal rainfall to local intraseasonal SST. For the atmosphere-only run (daily in Table 1), the maximum correlation coefficients between intraseasonal rainfall and underlying SST are considerably reduced over both the eastern Arabian Sea (Fig. 12a) and the Bay of Bengal (Fig. 12b); being only about $0.4 / 0.3$. In addition, they occur when rainfall and SST are almost in phase.

One cause of the different phase relationship between the rainfall and SST in the two runs is the different starting point of the two solutions: Both solutions have the same initial conditions, but the daily run is forced by SST from the last $10 \mathrm{yr}$ of the coupled run; as a result, there is an inconsistency between initial conditions in the two cases (for the last $10 \mathrm{yr}$ ). Another cause is truncation error in the SST field that forces the atmosphere-only model, which is of the order of $0.002^{\circ} \mathrm{C}$ compared to the SST that is directly passed to atmospheric model in the coupled run. To separate the impacts of errors from these two sources, we conducted several sensitivity experiments. Results from these experiments (figure not shown) indicate that, once the initial conditions have only a 1-day difference or the SST forcing field has truncation error, the stand-alone atmospheric model generates a solution of the same type as in the daily run (Fig. 12), that is, with rainfall and SST being almost in phase and less correlated when compared to those in the coupled run. The reduced correlation coefficient suggests that the NPISOs in the atmosphere-only run are not closely tied to underlying SST as in the coupled run. The loss of a coherent evolution between convection and SST may be the fundamental cause for the weaker NPISOs in the atmosphere-only run (Fig. 4). 

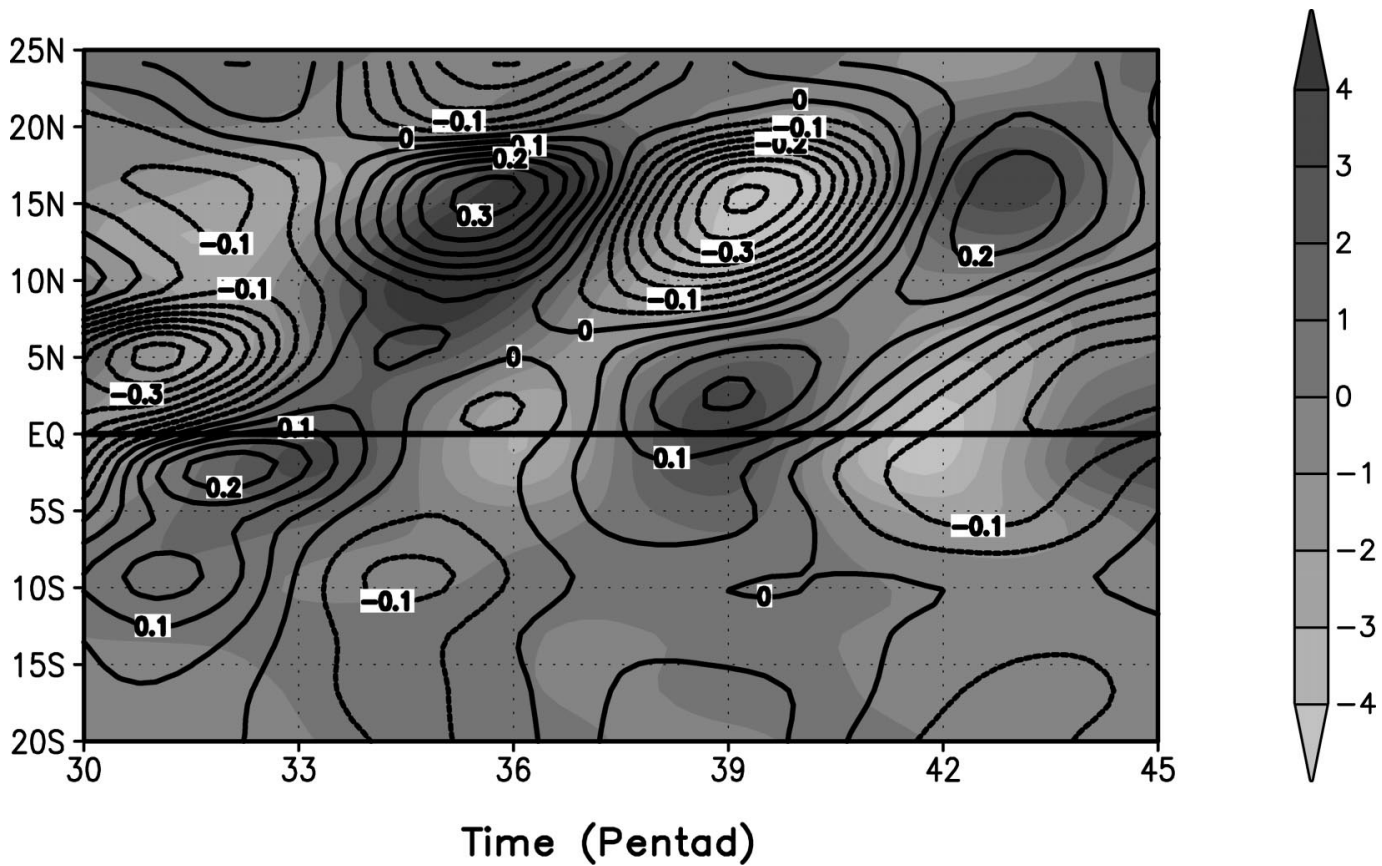

FIG. 10. Same as in Fig. 5 except that the results are the ensemble mean from 10 stand-alone atmospheric runs forced with daily sea surface temperature from the coupled model (daily9, Table 1).

\section{b. Interactions of NPISOs with the mean state}

In boreal summer, the dominant propagating direction of intraseasonal oscillations (ISOs) in the Indian Ocean is northward, rather than southward (Fig. 4a). The preferable northward propagation is partially attributed to the interactions between the convective disturbances and summer-mean state through the change of ocean surface temperature. The detailed temporal evolutions of the spatial patterns associated with the northward-propagating wet (dry) cycle from pentad 32 to 38 (Fig. 5) have been used to illustrate this idea.

At pentad 32, a positive convective anomaly appears in the western equatorial Indian Ocean and two negative convective zones occur in its north and east, respectively (Fig. 13a). Positive SST anomalies are observed in association with the negative convective zones over the Arabian Sea and the central-eastern equatorial Indian Ocean (Fig. 13b). These positive SST anomalies are due to both the decrease of latent heat flux (Fig. 13c) and increase of solar radiation (Fig. 13d). No significant positive SST anomaly is observed in the southern Indian Ocean. As discussed next, this asymmetry is primarily determined by the distributions of mean circulations and clouds.

The summer-mean low-level wind is southwesterly in the northern Indian Ocean, but southeasterly in the southern Indian Ocean (Fig. 2). The Kelvin wave response east of the convection (Gill 1980) intensifies easterlies in the southern Indian Ocean, but reduces the westerlies in the northern Indian Ocean. Thus, the latent heat flux increases in the southern Indian Ocean, but decreases in the northern Indian Ocean (Fig. 13c). This favors the development of positive (negative) SST anomaly in the northern Indian Ocean (southern Indian Ocean). Similar processes occur with the poleward-emanating Rossby waves. For the northern Rossby-like vortex, the latent heat flux reduces at its north side. For the southern Rossby-like vortex, the latent heat flux increases at its south side. Therefore, a significant positive SST anomaly appears in the north edge of the northern vortex. No positive SST anomaly, however, will appear along the south edge of the southern vortex. Further, the mean cloud amount in the Indian Ocean sector is much larger north of $10^{\circ} \mathrm{S}$ than south of it (Fig. 2). The descending motion associated with the convection anomaly in the western equatorial Indian Ocean significantly reduces cloud amount in the northern and equatorial central-eastern Indian Ocean relative to that in the southern Indian Ocean. As a consequence, large positive solar radiation anomalies are generated north and east of the positive equatorial convection, rather than south of it (Fig. 13d). The responses of both evaporation and solar radiation to equatorial convection thus favor the development of a positive SST anomaly in the northern Indian Ocean. The positive solar radiation in the equatorial central-eastern Indian Ocean (Fig. 13d) leads to the occurrence of positive SST anomaly in this region, which probably contributes to the eastward moving of the equatorial convection.

After two pentads (pentad 34, Fig. 14a), the equatorial positive convection has moved to the central-eastern Indian Ocean. The northern vortex intensifies and quickly moves northward due to the significant positive SST 


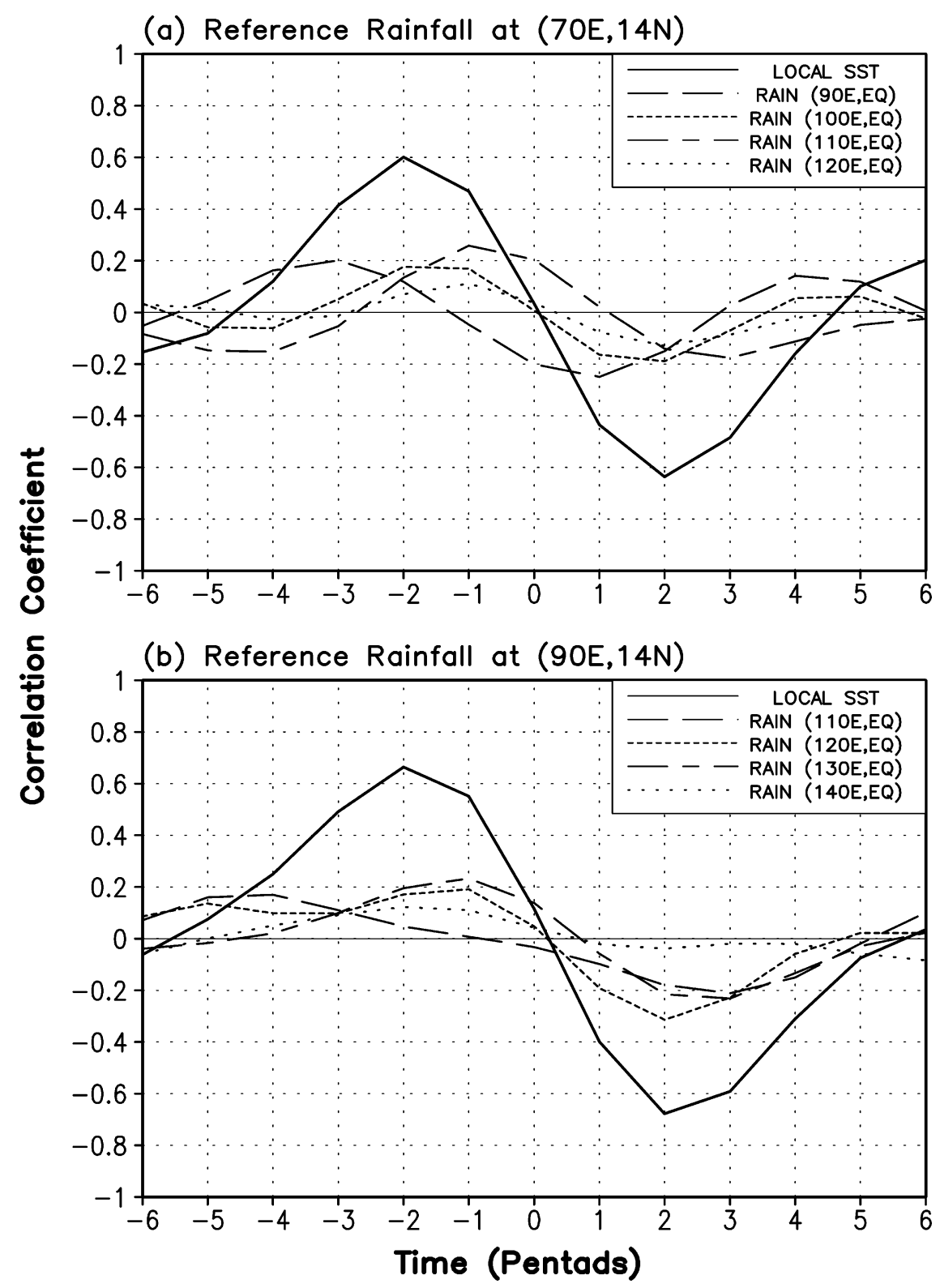

FIG. 11. The lag correlations of (a) intraseasonal rainfall over the Arabian Sea $\left(14^{\circ} \mathrm{N}, 70^{\circ} \mathrm{E}\right)$ with local SST and equatorial rainfall at $\left(90^{\circ}, 100^{\circ}, 110^{\circ}\right.$, and $\left.120^{\circ} \mathrm{E}\right)$, (b) intraseasonal rainfall over the Bay of Bengal $\left(14^{\circ} \mathrm{N}, 90^{\circ} \mathrm{E}\right)$ with local SST and equatorial rainfall at $\left(110^{\circ}, 120^{\circ}, 130^{\circ}\right.$, and $140^{\circ} \mathrm{E}$ ) using 10 -yr boreal summer output from the coupled run.

anomaly in the Arabian Sea (Fig. 14b). The southern vortex, however, dramatically weakens due to the lack of positive SST support. The leading easterly perturbation ahead of the convection in the northern Arabian Sea and the Bay of Bengal is very similar to the observations (Vecchi and Harrison 2002). A dry cycle starts in the equatorial western Indian Ocean. The positive SST in the Arabian Sea and near the equatorial central Indian Ocean is covered by negative surface heat flux (Fig. 14b), which indicates that the convection has moved into these regions and started to cool the underlying sea surface. The strong negative SST anomaly in pentad 32 over the Bay of Bengal is eroded by positive surface heat flux and gradually becomes positive. Negative solar radiation dominates in the Arabian Sea and the central equatorial Indian Ocean. Both reduced latent heat flux and increased solar radiation act to warm up the Bay of Bengal.

At pentad 36, the suppressed convection occupies all the equatorial Indian Ocean (Fig. 14c). The positive SST in the Bay of Bengal (Fig. 14d) leads the equatorial convection to move northward. Over the Indian peninsula a wet phase starts to prevail. At the same time, the equatorial convection moves eastward into the Mar- 


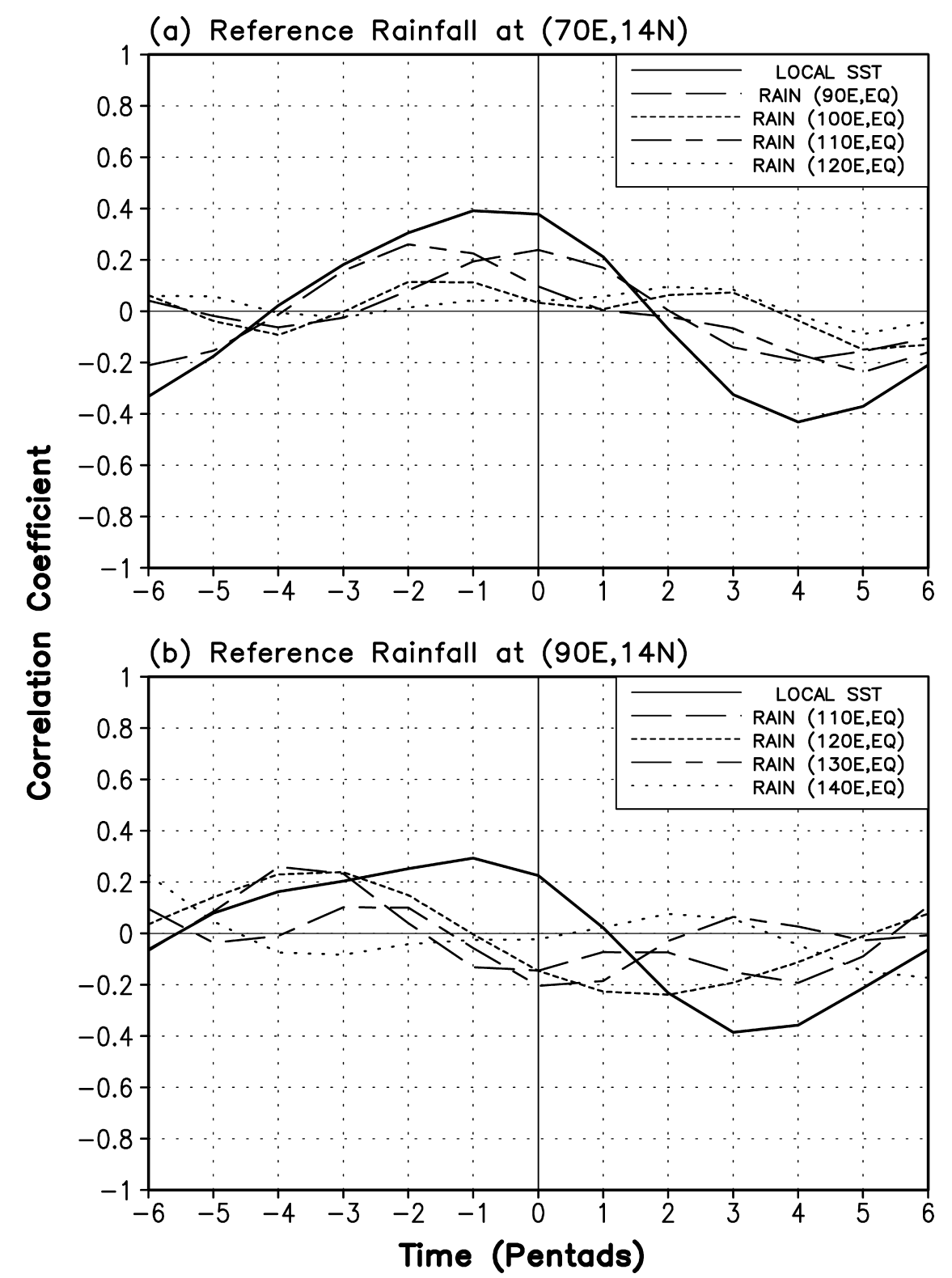

FIG. 12. Same as in Fig. 11 except that the results are from the stand-alone atmospheric run forced with the daily SST of the coupled model (daily, Table 1).

itime Continent. The tilted convection band extending from the Arabian Sea to the Maritime Continent resembles the Kelvin-Rossby wave packet suggested by Wang and Xie (1997). At the same time, another positive SST anomaly starts to develop in the equatorial western Indian Ocean due to the positive surface heat flux associated with the suppressed convection (Fig. 14d).

At pentad 38, the positive convections in the Arabian Sea and the Bay of Bengal keep moving in the northeast direction (Fig. 14e). The Indian subcontinent is occupied by a wet phase and a cyclonic circulation. Most parts of the Arabian Sea and the Bay of Bengal are covered by negative SST anomalies (Fig. 14f). A pos- itive SST belt develops near the equator. Positive convection reappears in the equatorial western Indian Ocean, suggesting that another intraseasonal cycle is coming on the stage.

\section{Relationship of NPISOs to eastward- propagating disturbances}

As mentioned in the introduction, one hypothesis for the cause of NPISOs in the Indian sector is that they are one aspect of the equatorial eastward-moving Kelvin-Rossby wave packet. If this mode is the dominant mechanism for NPISOs in our coupled solution, 


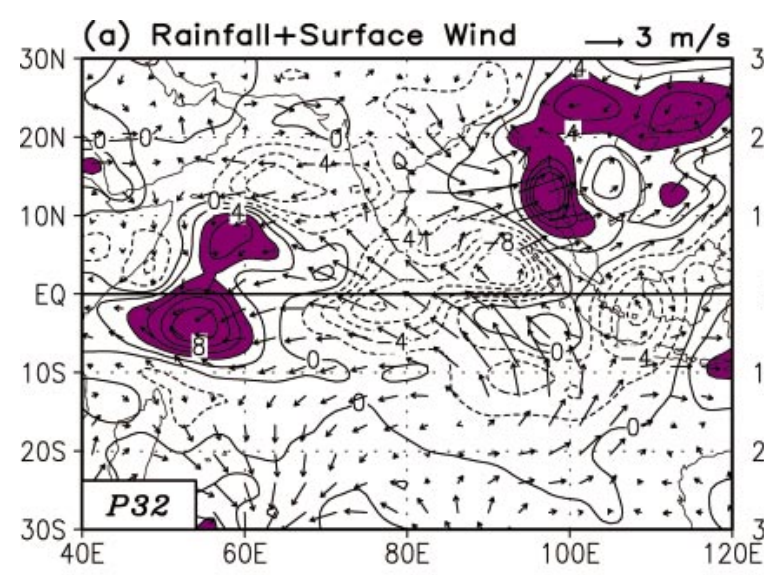

(b) SST (C)+ Qnet (W/m**2)
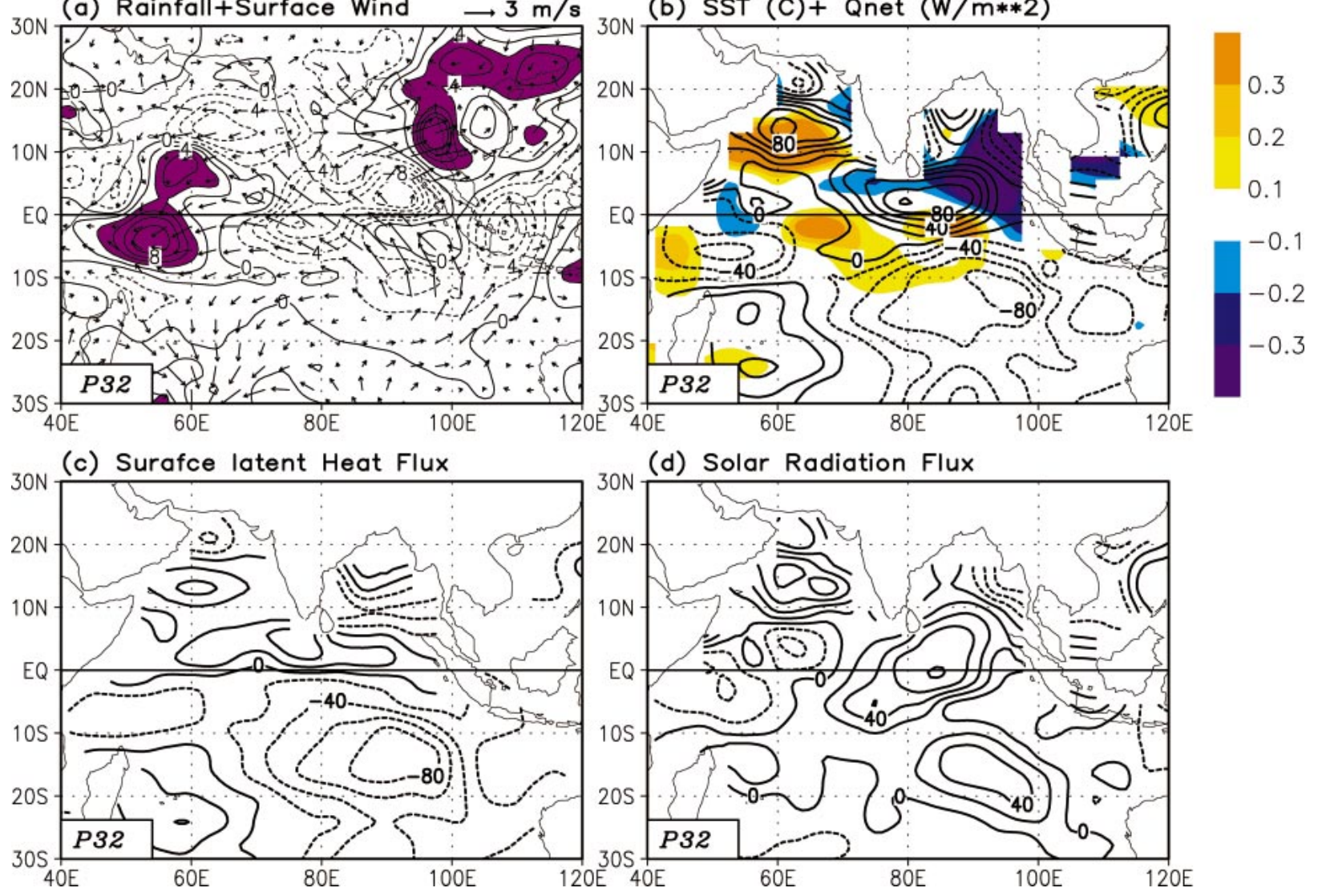

(d) Solar Radiation Flux

FIG. 13. Intraseasonal perturbations at pentad 32: (a) rainfall rate and surface winds, (b) sea surface temperature $\left({ }^{\circ} \mathrm{C}\right.$; shading) and net surface heat flux (contours), (c) surface latent heat flux, and (d) solar radiation. The contour interval of rainfall is $2 \mathrm{~mm}^{-1 a y}{ }^{-1}$, larger than 4 is shaded; the contour interval for heat flux is $20 \mathrm{~W} \mathrm{~m}^{-2}$. The positive heat flux means downward.

the off-equatorial convection, should move eastward with a similar phase speed to that of the equatorial convection. To test this relationship, Fig. 15 plots the temporal evolutions of intraseasonal rainfall perturbations along the equator and along $10^{\circ} \mathrm{N}$ from pentad 30 to 45. The equatorial rainfall perturbations associated with two northward events (Fig. 5) systematically moves eastward along with the SST perturbations across the Indian Ocean and Maritime Continent (Fig. 15a). Consistent with the latitude-time plot in Fig. 5, the positive SST anomalies lead the positive rainfall by about 2-3 pentads along the equator. At $10^{\circ} \mathrm{N}$, the first dry (wet) cycle follows well the equatorial convection and moves eastward (Fig. 15b). The second cycle, however, particularly its wet phase, does not move eastward following the equatorial convection. In contrast to the equatorial eastward movement, it moves westward from $100^{\circ} \mathrm{E}$ at pentad 41 to $50^{\circ} \mathrm{E}$ at pentad 44 . Interestingly, the lead of the SST anomaly to the rainfall perturbation still holds. For example, in the second cycle the underlying SST also shows westward propagation that leads the positive rainfall by 2-3 pentads (Fig. 15c). This result shows that some intraseasonal disturbances in the northern Indian Ocean do move eastward follow- ing the equatorial convection as suggested by Wang and Xie (1997), but some do not. In all cases, however, the intraseasonal disturbances in the northern Indian Ocean seem more closely related to the local SST anomalies 2-3 pentads ago.

To generalize the earlier case study, we conducted several statistical analyses with 10-yr output from the coupled run. Figure 16 shows regressed intraseasonal rainfall patterns in boreal summer (May-September) with the intraseasonal rainfall over the Arabian Sea and the Bay of Bengal. Both results from the coupled model and observations (CMAP dataset) are presented. When the reference point is in the eastern Arabian Sea $\left(14^{\circ} \mathrm{N}\right.$, $70^{\circ} \mathrm{E}$ ), the primary pattern of rainfall in the Indian sector is a north-south dipole structure, with positive rainfall over the Arabian Sea and the Bay of Bengal and negative rainfall near the equator (Figs. 16a,b). The model produces stronger negative anomaly near the equator compared to the observations. Although a positive rainfall anomaly is found over the Maritime Continent, it is separate from the positive rainfall over the Arabian Sea and the Bay of Bengal.

A similar situation exists for the reference point in the Bay of Bengal (Figs. 16c,d). In the Indian sector, 


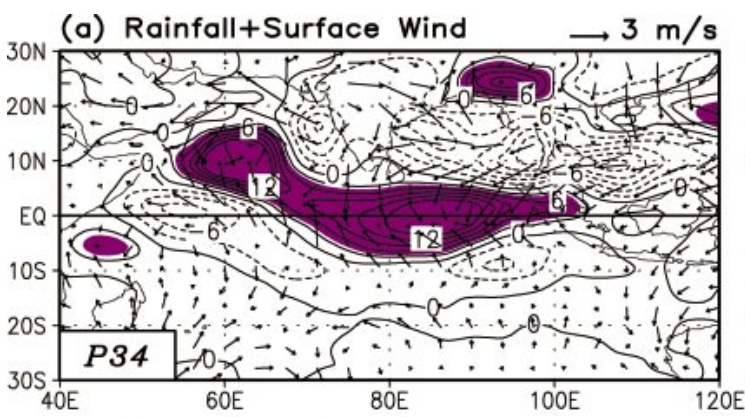

\section{(b) SST (C)+ Qnet (W/m**2)}
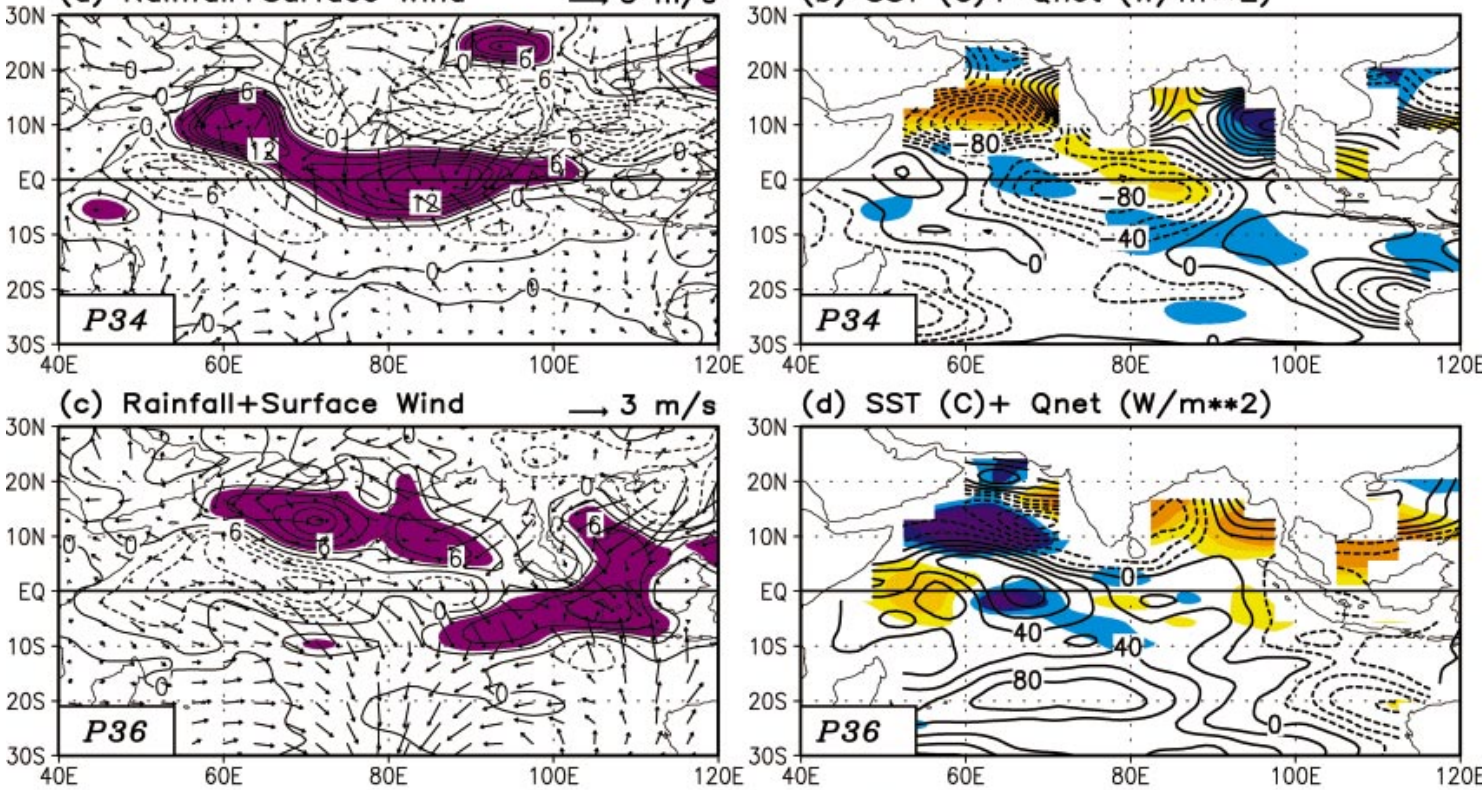

(d) SST (C)+ Qnet (W/m**2)

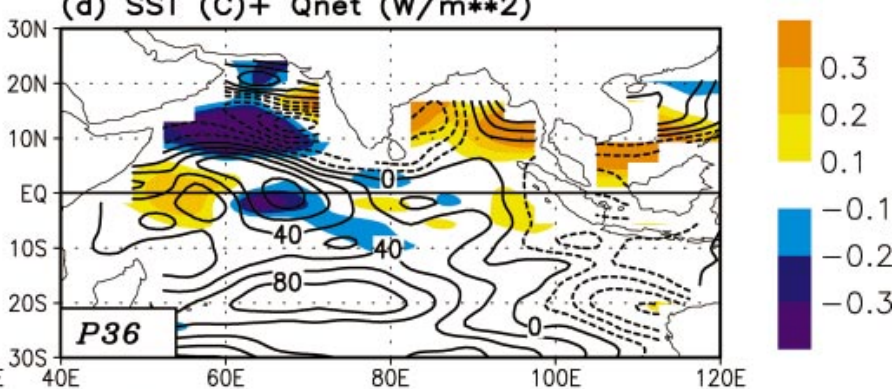

(e) Rainfall+Surface Wind $\longrightarrow 3 \mathrm{~m} / \mathrm{s}$
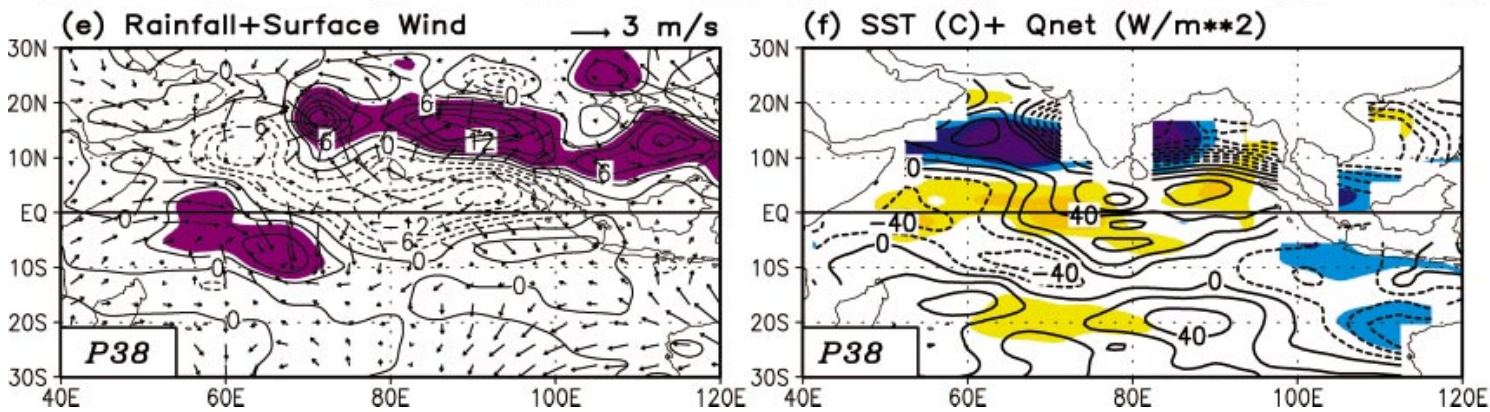

FIG. 14. Intraseasonal perturbations of rainfall rate and surface winds at pentad (a) 34, (c) 36, and (e) 38; and sea surface temperature $\left({ }^{\circ} \mathrm{C}\right.$; shading) and net surface heat flux (contours) at pentad (b) 34, (d) 36, and (f) 38 . The contour interval of rainfall is $2 \mathrm{~mm}^{\text {day }}{ }^{-1}$, larger than 4 is shaded; the contour interval for heat flux is $20 \mathrm{~W} \mathrm{~m}^{-2}$. The positive heat flux means downward.

the dominant pattern is the north-south dipole. There is a tilted positive rainbelt stretching from the Bay of Bengal to the northwest Pacific. This rainfall pattern is consistent with the intraseasonal OLR pattern of Sengupta et al. (2001). There is, however, no obvious Kelvin-Rossby wave packet either in the coupled solution or the CMAP data, implying that the mechanism suggested by Wang and Xie (1997) and Lawrence and Webster (2002) may be not the dominant process for NPISOs. Finally, it is worth indicating that intraseasonal rainfall over the Indian peninsula (south of $20^{\circ} \mathrm{N}$ ) is not only correlated with the signals over the Bay of Bengal (which has been emphasized by Bhat et al. 2001; Vecchi and Harrison 2002), but also with the rainfall over the Arabian Sea.

Finally, we estimate the lag correlations between the intraseasonal rainfall in the Arabian Sea and the Bay of Bengal with equatorial rainfall [at $\left(90^{\circ}, 100^{\circ}, 110^{\circ}\right.$, and $\left.120^{\circ} \mathrm{E}\right)$ and $\left(110^{\circ}, 120^{\circ}, 130^{\circ}\right.$, and $\left.\left.140^{\circ} \mathrm{E}\right)\right]$ in $10 \mathrm{yr}$ of boreal summers. The results for the coupled run and atmosphere-only run are presented in Figs. 11 and 12, respectively. In the coupled run, a lead of equatorial rainfall can be found for the Bay of Bengal (Fig. 11b), but not for the Arabian Sea (Fig. 11a). The correlation coefficients are usually below 0.3 , which are much smaller than the maximum correlation coefficient (about 0.6) between rainfall and local SST (with 2-pentad lead) in both the Arabian Sea and the Bay of Bengal. The situation is quite different for the atmosphere-only run (Fig. 12). In this case, the equatorial rainfall at $110^{\circ} \mathrm{E}$ shows a lead to rainfall in the Arabian Sea with a maximum correlation coefficient below 0.3 , same as in the Bay of Bengal. Because the maximum lead correlation of local SST to the rainfall is considerably reduced in the atmosphere-only run, the lead of equatorial rainfall becomes relatively important, particularly in the Bay of Bengal (Fig. 12b). These results indicate that the NPISOs may be more closely related to MJOs in the atmosphere-only model. In contrast, in the coupled solution the NPISOs are more strongly tied to underlying SST. 

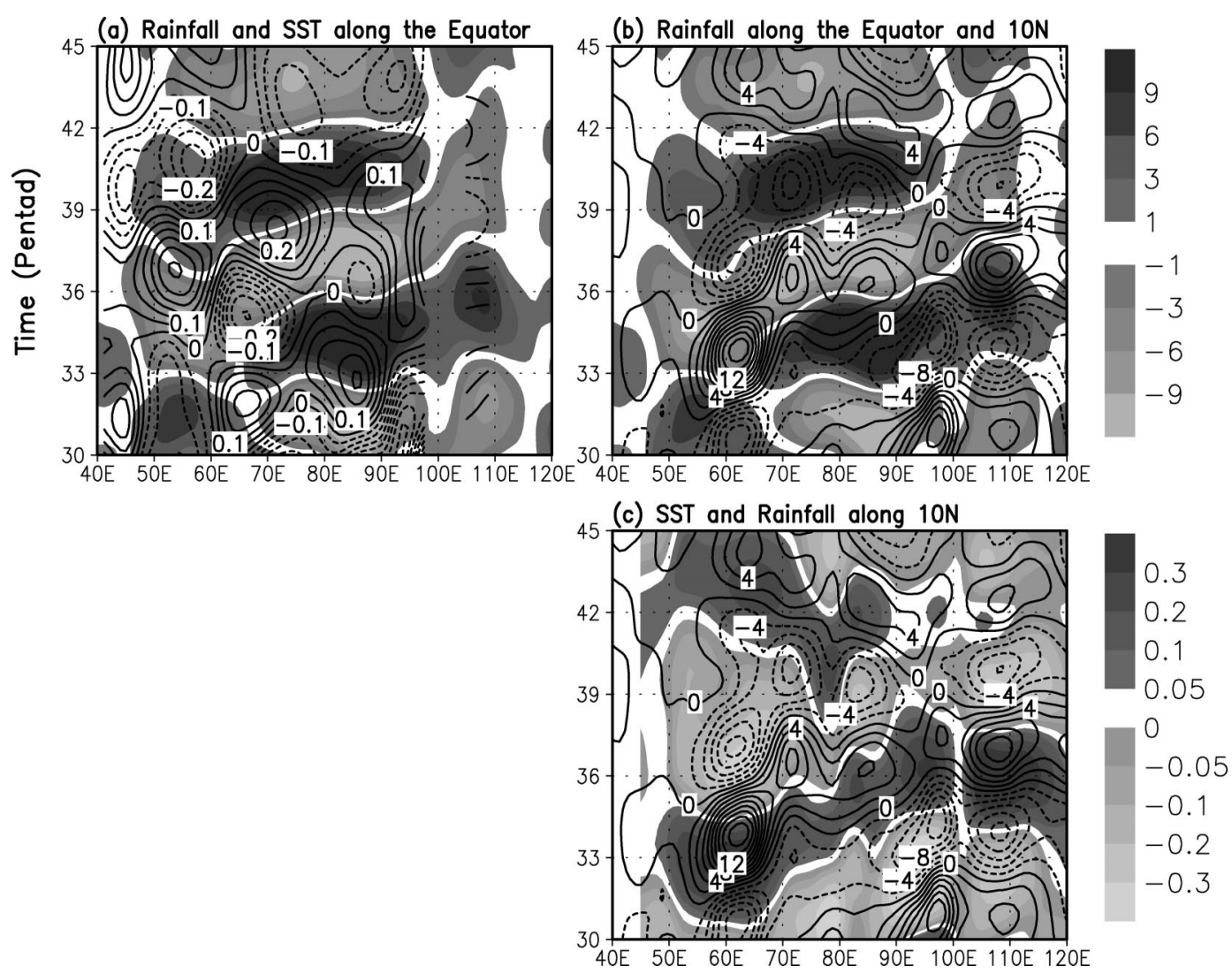

FIG. 15. Longitude-time Hovmoeller diagrams of intraseasonal variability on the equator and $10^{\circ} \mathrm{N}$ : (a) rainfall rate ( $\mathrm{mm}$ day $^{-1}$; shading) and sea surface temperature along the equator (contours), (b) rainfall rate along the equator (shading) and $10^{\circ} \mathrm{N}$ (contours), and (c) sea surface temperature (shading) and rainfall rate along $10^{\circ} \mathrm{N}$ (contours). The contour interval of SST in (a) is $0.05^{\circ} \mathrm{C}$; the contour interval of rainfall rate in (b) and (c) is $2 \mathrm{~mm}^{-1 a y^{-1}}$.

\section{Summary and discussion}

Using an atmosphere-ocean coupled model, we have shown that the simulated NPISOs in the Indian sector are strongly coupled with the underlying sea surface temperature, with intraseasonal SST anomalies enhancing NPISOs significantly (Fig. 4). Even forced with daily mean SST from the coupled model, however, the stand-alone atmospheric model (with noise in the initial and/or boundary conditions) is unable to reproduce the strength of NPISOs (Figs. 4, 10) and their phase relationship with underlying SST (Figs. 11, 12). The prevalent northward, rather than southward, propagation of boreal summer ISOs partially results from an interaction among the asymmetric summer-mean climate, atmospheric disturbances, and ocean surface temperature over the Indian sector (Fig. 13). The intraseasonal disturbances in the northern Indian Ocean are more closely related to the underlying SST, rather than the equatorial eastward-moving convection (Fig. 11). Finally, we suggest that the intraseasonal SST signal in the northern Indian Ocean is a useful index, which may be used to forecast the active (break) spells of south Asian summer monsoon with a lead of at least 2 pentads (10 days).

In our coupled run, both intraseasonal atmospheric convection and underlying SST propagate northward in the Indian Ocean sector with similar phase speeds. The convection and SST have a quadrature phase shift. The peak warm SST lags (leads) the peak dry phase (peak wet phase) by about 2-3 pentads. An analysis of the heat budget of the oceanic mixed layer indicates that the intraseasonal SST anomalies associated with NPISOs are primarily caused by the changes of surface heat flux and mixed-layer base entrainment, and that the contributions from horizontal advection and diffusion are negligible. In the surface heat flux, the dominant contributors are solar radiation and latent heat flux. This result is consistent with previous observational studies (Sengupta and Ravichandran 2001; Sengupta et al. 2001).

The fact that the strongest NPISOs occur in the coupled run, compared to the daily and mean runs (Table 1), suggests that SST feeds back to atmospheric convection. The significant rainfall response in the 10-ensemble daily9 experiment directly shows that the intraseasonal SST does feed back to the intraseasonal atmospheric convection. In the ECHAM4 model, the intraseasonal SST anomalies influence the convection through changing the surface heat fluxes and convective instability. 
(a) Reference at $(70 \mathrm{E}, 14 \mathrm{~N})$

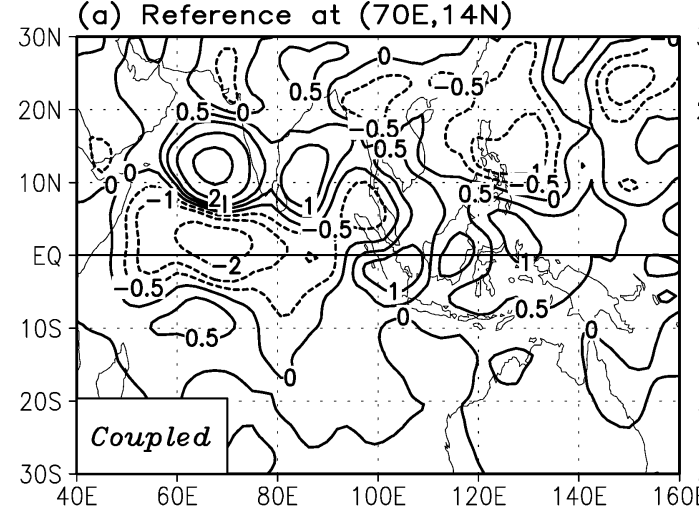

(c) Reference at $(90 \mathrm{E}, 14 \mathrm{~N})$

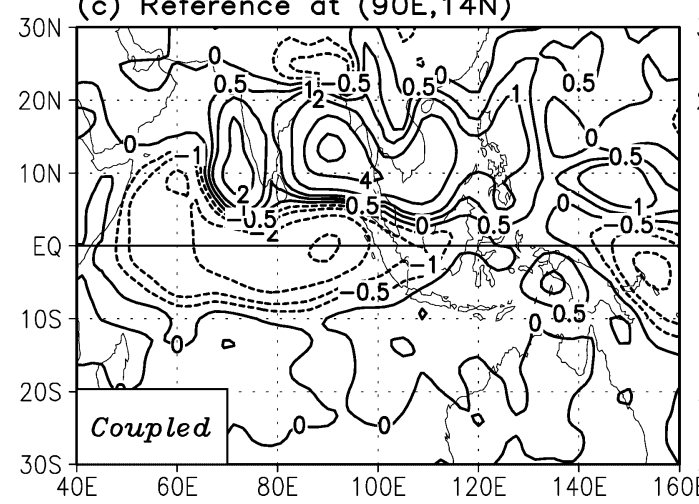

(b) Reference at $(70 E, 14 N)$

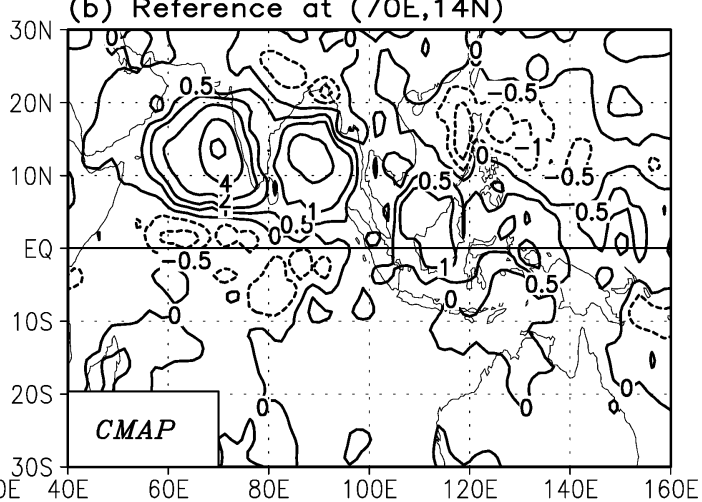

(d) Reference at $(90 \mathrm{E}, 14 \mathrm{~N})$

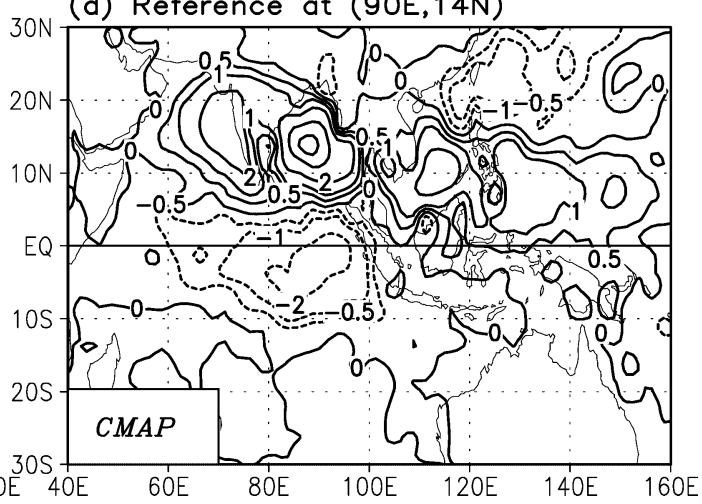

FIG. 16. Regressed rainfall rate $\left(\mathrm{mm} \mathrm{day}^{-1}\right)$ of the boreal summer intraseasonal oscillation with reference point over the Arabian Sea $\left(14^{\circ} \mathrm{N}, 70^{\circ} \mathrm{E}\right)$ for the (a) coupled model and (b) CMAP dataset; with reference point over the Bay of Bengal $\left(14^{\circ} \mathrm{N}, 90^{\circ} \mathrm{E}\right)$ for the (c) coupled model, and (d) CMAP dataset.

The prevalent northward rather than southward propagation of NPISOs over the Indian sector is partially explained by an interaction among summer-mean atmospheric circulations, atmospheric disturbances, and ocean surface temperature. Once a positive convection appears in the equatorial western Indian Ocean, the associated atmospheric responses generate significant positive SST anomalies to the north and east of it, leading the convection to propagate northward and eastward. This SST response pattern is largely determined by the basic states of Indian Ocean in boreal summer. 1) The summer-mean surface wind is southeasterly in the southern Indian Ocean and southwesterly in the northern Indian Ocean. The responses of Rossby waves and Kelvin wave to the equatorial convection reduce (strengthen) the surface wind speed in the northern (southern) Indian Ocean. The resultant changes of latent heat flux and oceanic mixed-layer entrainment warm up the northern Indian Ocean, but cool the southern Indian Ocean. 2) The summer-mean cloud amount in the equatorial and northern Indian Oceans is larger than that in the southern Indian Ocean. Therefore, the subsidence associated with the equatorial convection strongly reduces the cloud cover to the north and east of it. In these regions, downward solar radiation increases, further warming up the sea surface. 3) The mixed-layer thickness in the equa- torial and northern Indian Ocean is systematically shallower than that in the southern Indian Ocean. Therefore, even forced with the same surface heat flux perturbation, larger SST anomaly will occur in the equatorial and northern Indian Ocean rather than in the southern Indian Ocean. The easterly and subsidence anomalies ahead of the convection keep warming up the sea surface north of the convection through reducing the upward latent heat flux (and entrainment) and increasing the downward solar radiation. Therefore, the convection associated with intraseasonal oscillation keeps moving northward.

The NPISOs are more closely linked with the northern Indian Ocean SST than with the equatorial eastwardmoving Madden-Julian oscillation. Regressed analysis with the intraseasonal rainfall over the Arabian Sea and the Bay of Bengal (Fig. 16) does not find a clear horseshoe-shaped Kelvin-Rossby wave packet, which is necessary to support the hypothesis that NPISO is a component of the eastward-moving convection (Wang and Xie 1997; Lawrence and Webster 2002). On the other hand, the relationship between the NPISOs and MJOs may be monthly dependent. As indicated by KemballCook and Wang (2001), in early summer (May-June) these two could be highly correlated. The independent 
NPISOs may be dominant in other summer months (July-August-September).

The significant lead of intraseasonal SST to convection over the northern Indian Ocean provides a useful index for the forecast of active (break) spells in the south Asian summer monsoon. Using 3-yr observational data, Vecchi and Harrison (2002) has found that subseasonal sea surface temperature variability in the Bay of Bengal is a good predictor of monsoon breaks over the Indian subcontinent. Intraseasonal convection, however, not only propagates from the Bay of Bengal to the Indian subcontinent, but also from the Arabian Sea. To know the spatial pattern of intraseasonal SST over the whole northern Indian Ocean may provide a better predictor for monsoon active (break) spells in the Indian subcontinent.

The concurrence of atmospheric subsidence and positive SST in the coupled run is important for the 2pentad lag of atmospheric convection to the underlying SST. It is clear that intraseasonal SST fluctuations in the Indian Ocean represent not only a boundary forcing for the atmosphere but also are a result of atmospheric convection (Waliser and Graham 1993). Therefore, the attempt to reproduce observed ISOs through forcing atmosphere-only models with the observed daily SST is likely impossible. Our previous study also showed that forcing an atmosphere-only model with observed monthly mean SST (AMIP-type run) tends to produce convective centers over highest SST in the Asia/western Pacific sector (Fu et al. 2002). In fact, the highest SST in the warm-pool region is caused by the atmospheric subsidence associated with diminished convection. Therefore, allowing atmosphere-ocean interaction in the warm-pool region may be a critical factor for successful simulations of the Asia/Pacific summer monsoon climatology and intraseasonal variability.

In this study, the important role of air-sea coupling on simulating northward-propagating boreal summer intraseasonal oscillation is suggested. The major atmospheric and oceanic processes involved in the model are identified. The study of air-sea coupling on the Asian monsoon climatology and its variability, however, is still in its infant stage; there are a lot of questions that need to be addressed with both modeling and observational studies, such as: What determines the period and propagating speed of NPISOs? Does air-sea coupling play any role in these aspects? Apparently, more coupled modeling studies are required to clarify to what degree the results obtained here are not model dependent. More long-term and accurate observational data are needed to validate models and examine the findings with numerical models.

Acknowledgments. The authors appreciate Drs. L. Bengtsson, E. Roeckner, L. Dumenil, and U. Schulzweida at the Max-Planck-Institut für Meteorologie for their kind help in the implementation of ECHAM4 AGCM at the International Pacific Research Center
(IPRC). We thank Ms. H. Teng for providing the codes of the wavenumber-frequency analysis. Comments from two anonymous reviewers helped improve the manuscript. This research was supported by the Climate Dynamics Program, National Science Foundation Award ATM 0073023 and by the Frontier Research System for Global Change through its sponsorship of the IPRC.

\section{REFERENCES}

Annamalai, H., and J. M. Slingo, 2001: Active/break cycles: Diagnosis of the intraseasonal variability of the Asian Summer Monsoon. Climate Dyn., 18, 85-102.

Bhat, G. S., and Coauthors, 2001: BOBMEX: The Bay of Bengal Monsoon Experiment. Bull. Amer. Meteor. Soc., 82, 2217-2243.

Chen, T. C., R. Y. Tzeng, and M. C. Yen, 1988: Development and life cycle of the Indian monsoon: Effect of the 30-50 day oscillation. Mon. Wea. Rev., 116, 2183-2199.

Dumenil, L., and E. Todini, 1992: A rainfall-runoff scheme for use in the Hamburg climate model. Advances in Theoretical Hydrology, A Tribute to James Dooge, European Geophysical Society Series on Hydrological Sciences, Vol. 1, Elsevier Press, $129-157$.

Fu, X., and B. Wang, 2001: A coupled modeling study of the annual cycle of Pacific cold tongue. Part I: Simulation and sensitivity experiments. J. Climate, 14, 765-779.

- - , and T. Li, 2002: Impacts of air-sea coupling on the simulation of mean Asian summer monsoon in ECHAM4 model. Mon. Wea. Rev., 130, 2889-2903.

Gadgil, S., and J. Srinivasan, 1990: Low frequency variation of tropical convergence zones. Meteor. Atmos. Phys., 44, 119-132.

_ , and G. Asha, 1992: Intraseasonal variation of the summer monsoon. I: Observational aspects. J. Meteor. Soc. Japan, 70, 517527.

Gaspar, P., 1988: Modeling the seasonal cycle of the upper ocean. $J$. Phys. Oceanogr., 18, 161-180.

Gill, A. E., 1980: Some simple solutions for heat-induced tropical circulation. Quart. J. Roy. Meteor. Soc., 106, 447-462.

Hayashi, Y., 1982: Space-time spectral analysis and its applications to atmospheric waves. J. Meteor. Soc. Japan, 60, 156-171.

Kemball-Cook, S., and B. Wang, 2001: Equatorial waves and air-sea interaction in the boreal summer intraseasonal oscillation. J. Climate, 14, 2923-2942.

, - _ and X. Fu, 2002: Simulation of the intraseasonal oscillation in ECHAM-4 model: The impact of coupling with an ocean model. J. Atmos. Sci, 59, 1433-1453.

Krishnamurti, T. N., and D. Subrahmanyam, 1982: The 30-50 day mode at $850 \mathrm{mb}$ during MONEX. J. Atmos. Sci., 39, 2088-2095.

- P. K. Jayakumar, J. Sheng, N. Surgi, and A. Kumar, 1985: Divergent circulations on the 30 to 50 day time scale. J. Atmos. Sci., 42, 364-375.

Lau, K. M., and P. H. Chan, 1986: Aspects of the 40-50 day oscillation during the northern summer as inferred from outgoing longwave radiation. Mon. Wea. Rev., 114, 1354-1367.

Lawrence, D. M., and P. J. Webster, 2002: The boreal summer intraseasonal oscillation: Relationship between northward and eastward movement of convection. J. Atmos. Sci., 59, 1593-1606.

Madden, R., and P. R. Julian, 1971: Detection of a 40-50 day oscillation in the zonal wind in the tropical Pacific. J. Atmos. Sci., 28, 702-708.

Matsuno, T., 1966: Quasi-geostrophic motions in the equatorial area. J. Meteor. Soc. Japan, 44, 25-42.

Miller, M. J., T. N. Palmer, and R. Swinbank, 1989: Parameterization and influence of sub-grid scale orography in general circulation and numerical weather prediction models. Meteor. Atmos. Phys., 40, 84-109. 
Murakami, M., 1976: Analysis of summer monsoon fluctuations over India. J. Meteor. Soc. Japan, 54, 15-31.

Nanjundiah, R. S., J. Srinivasan, and S. Gadgil, 1992: Intraseasonal variation of the Indian summer monsoon. II: Theoretical aspects. J. Meteor. Soc. Japan, 70, 529-550.

Nordeng, T. E., 1995: Extended versions of the convective parameterization scheme at ECMWF and their impact on the mean and transient activity of the model in the tropics. ECMWF Research Dept. Tech. Memo. 206, European Centre for Medium-Range Weather Forecasts, Reading, United Kingdom, 41 pp.

Roeckner, E., and Coauthors, 1996: The atmospheric general circulation model ECHAM4: Model description and simulation of present-day climate. Max Planck Institute for Meteorology Rep. 218, $90 \mathrm{pp}$.

Rui, H., and B. Wang, 1990: Development characteristics and dynamic structure of tropical intraseasonal convection anomalies. J. Atmos. Sci., 47, 357-379.

Sengupta, D., and M. Ravichandran, 2001: Oscillations of Bay of Bengal sea surface temperature during the 1998 summer monsoon. Geophys. Res. Lett., 28, 2033-2036.

- B. N. Goswami, and R. Senan, 2001: Coherent intraseasonal oscillations of ocean and atmosphere during Asian summer monsoon. Geophys. Res. Lett., 28, 4127-4130.

Stendel, M., and E. Roeckner, 1998: Impacts of horizontal resolution on simulated climate statistics in ECHAM4. Max Planck Institute for Meteorology Rep. 253, 120 pp.

Taylor, K. E., D. Williamson, and F. Zwiers, 2000: The sea surface temperature and sea-ice concentration boundary condition for AMIP II simulations. PCMDI Rep. 60, Program for Climate Model Diagnosis and Intercomparison, Lawrence Livermore National Laboratory, Livermore, CA, 25 pp. [Available online at http:// www-pcmdi.llnl.gov/amip/AMIP2EXPDSN/BCS/amip2bcs.html]

Tiedtke, M., 1989: A comprehensive mass flux scheme for cumulus parameterization in large-scale models. Mon. Wea. Rev., 117, 1779-1800.

Vecchi, G., and D. E. Harrison, 2002: Monsoon breaks and subseasonal sea surface temperature variability in the Bay of Bengal. J. Climate, 15, 1485-1493.

Waliser, D. E., and N. E. Graham, 1993: Convective cloud systems and warm-pool SSTs: Coupled interactions and self-regulation. J. Geophys. Res., 98 (D7), 12 881-12 893.

Wang, B., and H. Rui, 1990: Synoptic climatology of transient tropical intraseasonal convection anomalies: 1975-1985. Meteor. Atmos. Phys., 44, 43-61.

_- T. Li, and P. Chang, 1995: An intermediate model of the tropical Pacific Ocean. J. Phys. Oceanogr., 25, 1599-1616.

oscillation. J. Atmos. Sci., 54, 72-86.

_ , and X. Fu, 2001: Physical processes determining the rapid reestablishment of the equatorial Pacific cold tongue/ITCZ complex from March to May. J. Climate, 14, 2250-2265.

Webster, P. J., 1983: Mechanisms of monsoon low-frequency variability: Surface hydrological effects. J. Atmos. Sci., 40, 21102124.

_ , and Coauthors, 2002: The JASMINE pilot study. Bull. Amer. Meteor. Soc., 83, 1603-1629.

Wheeler, M., and G. N. Kiladis, 1999: Convectively coupled equatorial waves: Analysis of clouds and temperature in the wavenumber-frequency domain. J. Atmos. Sci., 56, 374-399.

Yasunari, T., 1979: Cloudiness fluctuations associated with the Northern Hemisphere summer monsoon. J. Meteor. Soc. Japan, 57, 227-242.

_ 1 1980: A quasi-stationary appearance of 30 to 40 day period in the cloudiness fluctuations during the summer monsoon over India. J. Meteor. Soc. Japan, 58, 225-229.

1981: Structure of an Indian summer monsoon system with around 40-day period. J. Meteor. Soc. Japan, 59, 336-354. 